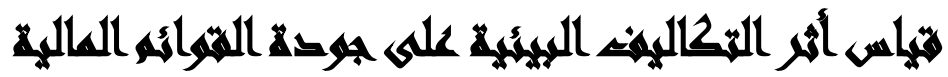

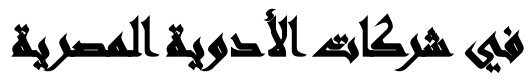

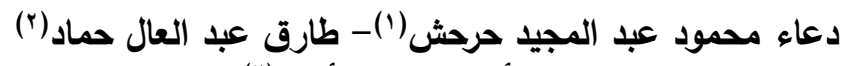

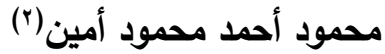

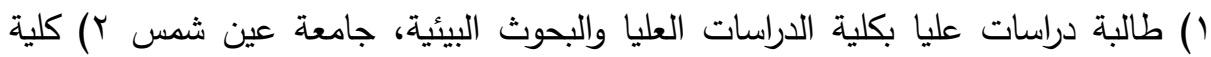

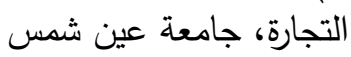

\section{المستخلتص}

تتاولت الدراسة قياس أثر التكاليف البيئية على جودة القوائم المالية. حيث هدفت الدئ الدراسة

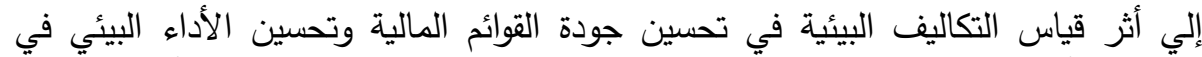

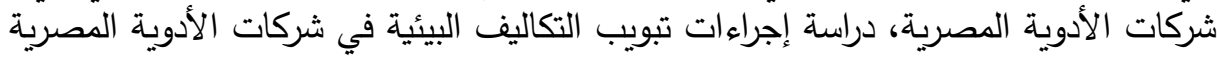

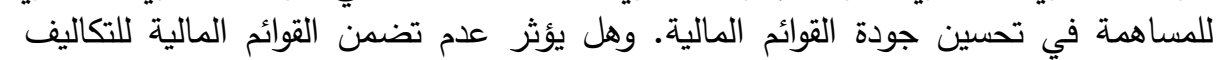

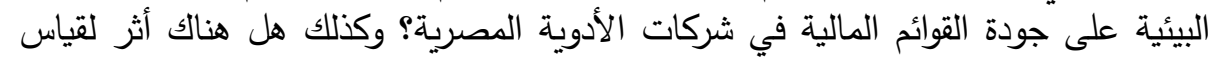

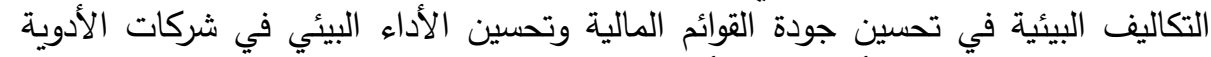

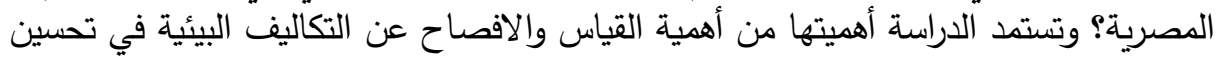

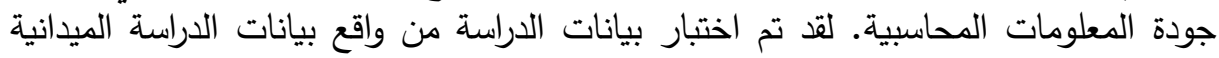

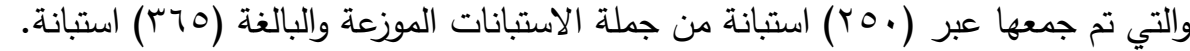

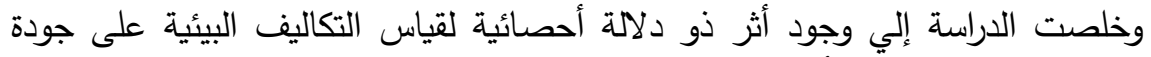

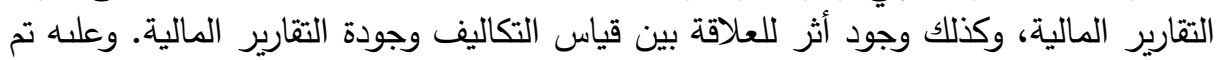
قبول فروض الدراسة.

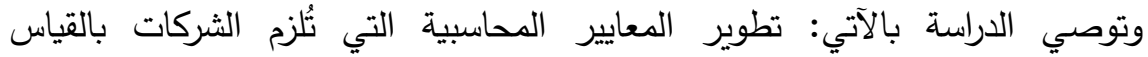

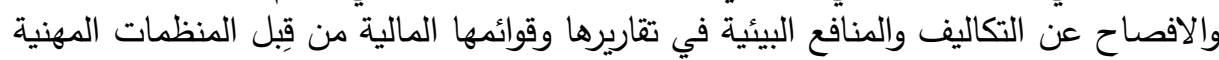

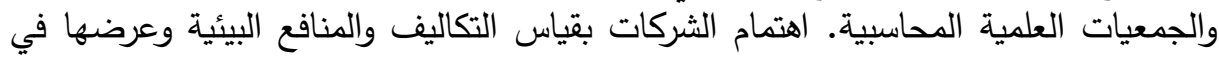

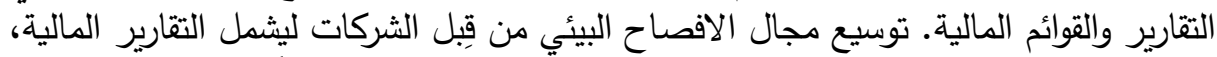

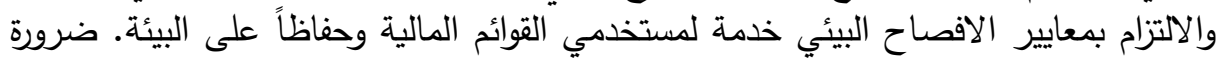

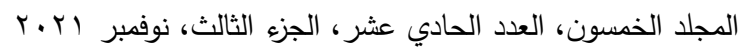

$$
\begin{aligned}
& \text { الترقيم الدولي 0826-0 الترني } \\
& \text { الترقيم الدولي الموحد الإلكتروني 3178-0826-2636 }
\end{aligned}
$$


قيام الشركات بقياس التكاليف والمنافع البيئية والافصاح عنها لتحسين جودة المعلومات

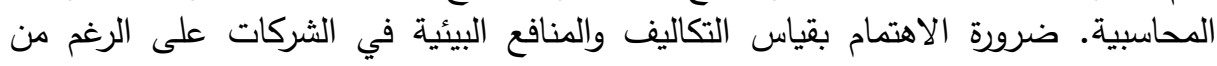

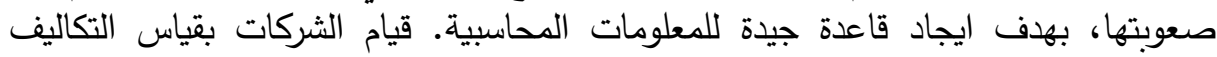
والمنافع البيئية بحيث تكون مُسجلة ومبوبه بشكل واضح ودقيق وعانت وعرضها في التقارير والتوائم

\section{ravall}

يعد الأداء البيئي أحد الاتجاهات الحديثة والمهمة التي نالت على اهتمام كبير في مختلف الدول والمجتمعات، وذلك يرجع للدور العظيم الذي تلعبه البيئة في حياة الانسان

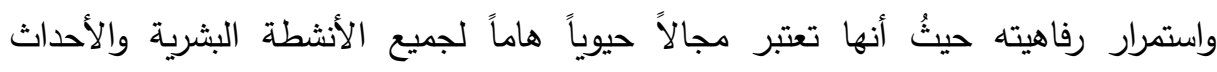

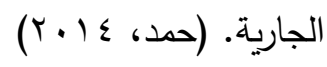

تطبيق محاسبة التكاليف يكتفي بحصر وحساب عناصر التكاليف المرتبطة بالثركة دون الأخذ في الاعتبار التكاليف البيئية، وبالتالي يؤدي ذلك إلي ظهور أرباح غير حقيقية، ويترتب

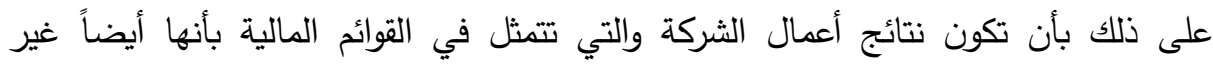

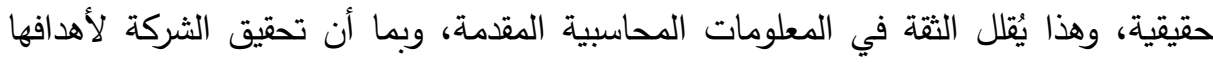

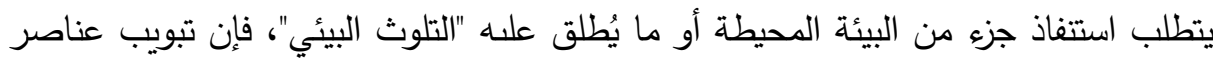

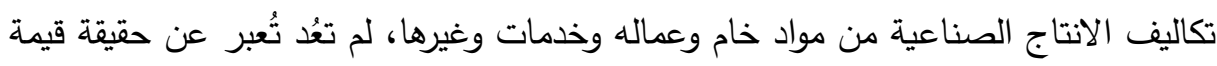

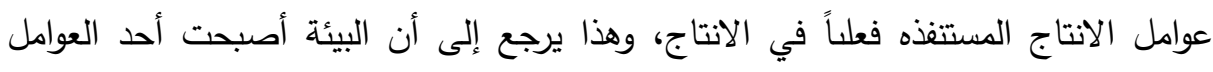

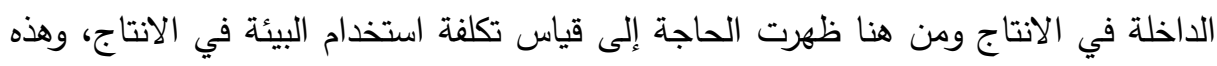

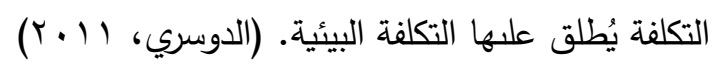
انطلاقاً مما سبق تتناول هذه الدراسة مدى قدرة النظام المحاسبي في المنشآت الصناعية على قياس كلاً من التكاليف والمنافع البيئية، وبيان أثر ذلك على هلى جودة التوان التوائم المالية وهل

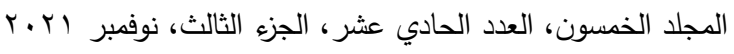

$$
\begin{aligned}
& \text { الترقيم الدولي 0826-0 الترني } \\
& \text { الترقيم الدولي الموحد الإكتروني 3178-2636 لكرلي }
\end{aligned}
$$


ذلك سيلعب دوراً في رفع كفاءة الأداء البيئي وجعل تلك التقارير المالية أكثر كفاءة وفعالية في

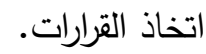

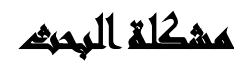

تعتبر المحاسبة البيئية أحدث مراحل التطور المحاسبي، وهذا التطور نشأ نتيجة للازدياد المنفرد في حجم وقرارات المؤسسات التي لها تأثيرات مالية واقتصادية واجتماعية وبيئية واسعة لهنية المدي، مما أدى إلى الاهتمام بها من قبل المؤسسات والجمعيات المحاسبية والمهنية والجهات الأكاديمية، ولما كان الإطار الفكري المحاسبي يعاني من القصور لعدم قدرته على تقديم

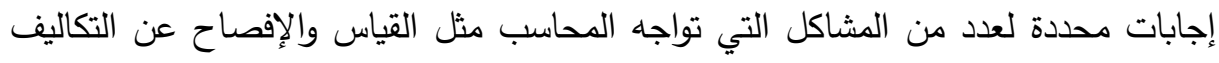

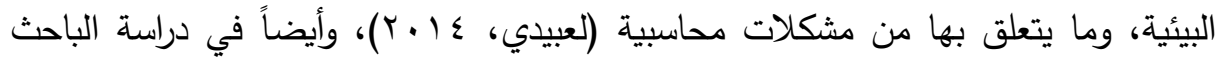

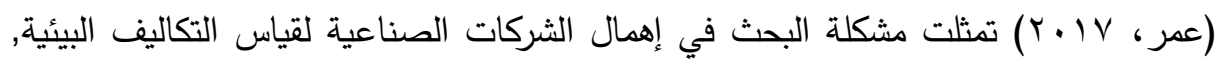

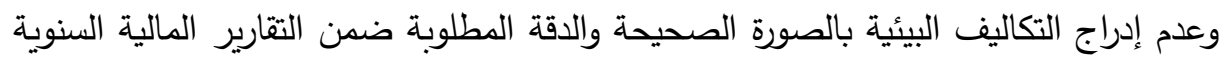
المنشورة، مما كان له أثر سلبي على جودة هذه التقارير المالية وعلى جودة القرارات المتخذة بلهي بواسطة مستخدمي تلك التقارير وبناءاً على ذلك سوف نراعي ذلك القصور فئ في هذه الدراسة

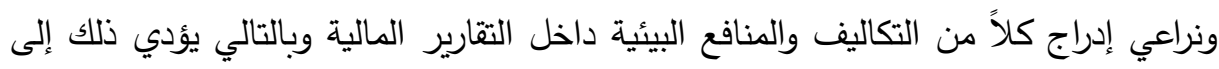
صحة اتخاذ القرارات من قبل المستخدمين. ومن هذا المنطلق يمكن صياغة الإثكالية الرئيسية لهذا البحث في السؤال الرئيسي التالي:

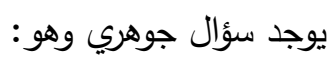
"ما أثر القياس والافصاح عن التكاليف والمنافع البيئية على جودة القوائم المالية لشركات

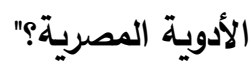
ويتقرع منه عدة أسئلة فرعية وهي: • ما أثر القياس والافصاح عن التكاليف البيئية على جودة القوائم المالية؟ ولئ

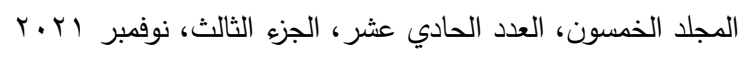


مجلة العلوم البيئية

كلية الدراسات العلا والبحوث البيئية - جامعة عين شمس البية

دعاء محمود حرحش وآخرون

• ما أثر القياس والافصاح عن المنافع البيئية على جودة القوائم المالية؟

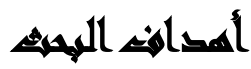

يتمثل الهدف الجوهري في: "بيان أثر التكاليف البيئية على جودة القوائم المالية في شركات الأدوية المصرية. والعمل على تخفيض تكاليف أسعار الأدوية، لتحسين الأداء البيئي والحرص على صحة وسلامة أفراد المجتمع". يستمد منه عدة أهداف فرعية:

• دراسة تأثير جودة القوائم المالية من خلال تضمنها للتكاليف البيئية على قرارات مستخدمي

$$
\text { المعلومات المحاسبية في شركات الأدوية المصرية. }
$$

• تحليل المعوقات التي تحد من تأثير كلاً من التكاليف البيئية على جودة القوائم المالية.

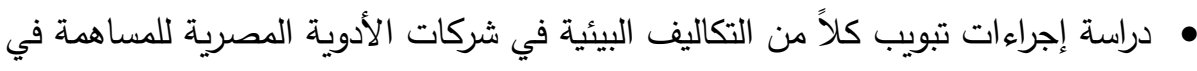
تحسين جودة القوائم المالية. • استتتاج أثر قياس التكاليف البيئية في تحسين جودة القوائم المالية وتحسين الأداء البيئي في شركات الأدوية المصرية.

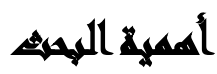

ظهرت أهمية محاسبة التكاليف البيئية من خلال الأبحاث والدراسات التطبيقية في الدول المتقدمة، كوسيلة لمساعدة الشركات في توفير قدر كبير من المعلومات عن التكاليف البيئية

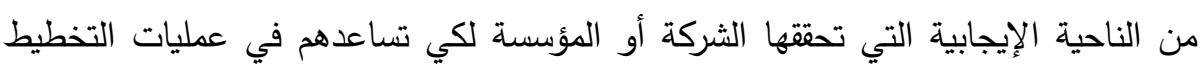
والرقابة على أنشطة تلك الشركات لتحسين الأداء البيئي، وتسهم في جعل قراراتهم تستند على لئي أسس صحيحة.

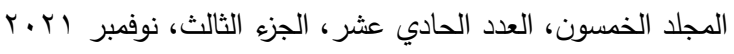

$$
\begin{aligned}
& \text { الترقيم الدولي 0826-0 الترني } \\
& \text { الترقيم الدولي الموحد الإكتروني 3178-2636 لكرلي }
\end{aligned}
$$


حيث أن معظم الثركات تتحمل أعباء مالية إضافية لحماية البيئة لتحسين صورة المؤسسة أو الثركة أمام المجتمع وبالرغم من أهمية نظام محاسبة التكاليف البيئية والاهتمام

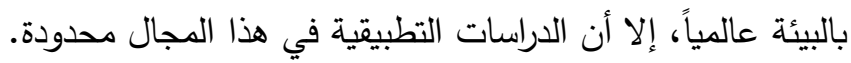
كما يستمد هذا البحث أهميته من خلال النقاط التالية:

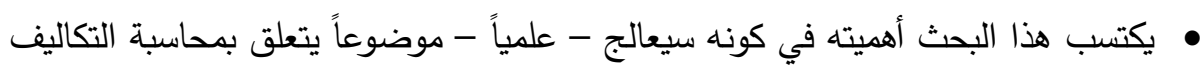
البيئية وأهيتها في تحسين جودة القوائم المالية.

• الرغبة في معرفة مدي تأثير التكاليف البيئية على جودة القوائم المالية.

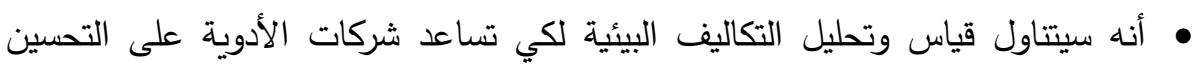
والتطوير المستمر وتقييم الأداء. • تحسين الظروف البيئية المحيطة بقطاع شركات الأدوية.

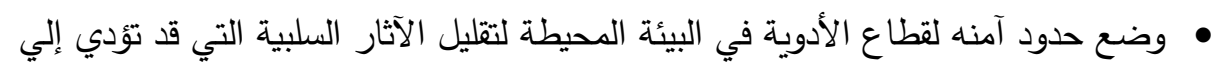
الإضرار بهذا القطاع. الوصول إلي نتائج وتوصيات ومقترحات تساعد متخذ القرار للاستفادة منها والعمل بها.

\section{هروض المهيه}

الفرض الرئيسي الأول: لا توجد علاقة معنوية بين قياس أثر التكاليف البيئية و جودة القوائم

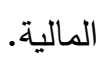
الفرض الرئيسي الثاني: لا توجد علاقة معنوية بين قياس التكاليف البيئية وكفاءة الأداء في شركات الأدوية.

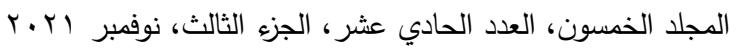

$$
\begin{aligned}
& \text { الترقيم الدولي 0826-0 الترني } \\
& \text { الترقيم الدولي الموحد الإكتروني 3178-2636 لأن }
\end{aligned}
$$




\section{همطلحائ الهمبه}

التكاليف البيئية: جميع النفقات التي تتحملها المنشأة بهدف تقليل أو منع الأضرار البيئية في

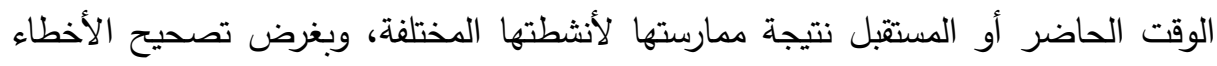
التي تترتب على قرارات قد اتخدتها والتي كان لها تأثير سلبي على البيئة وعلى المجتمع ككل.

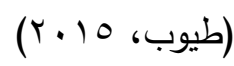
القوائم المالية: مجموعة كاملة من الحسابات تثتمل على الميزانية، قائمة تدفقات الخزينة، قائمة تغير الأموال الخاصة، قائمة حساب النتيجة، والهدف من هذه القوائم تقديم المعلومات المات

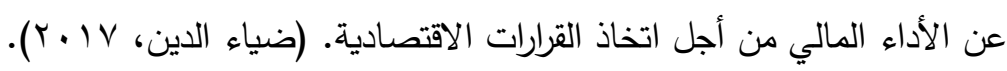

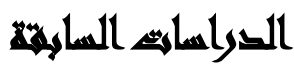

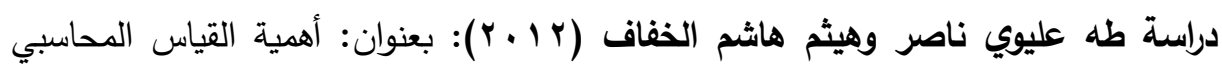
للتكاليف البيئية ودورها في تفعيل جودة المعلومات المحاسبية لاتخاذ القرارات - دراسة

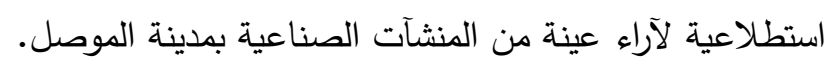

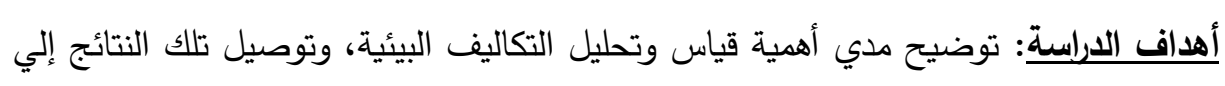
الجهات المعنية، بيان أثر قياس التكاليف البيئية على جودة القوائم المالية.

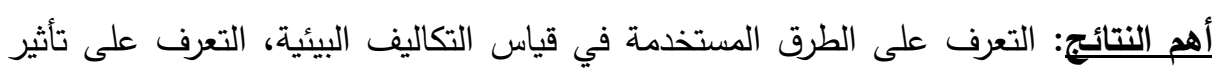

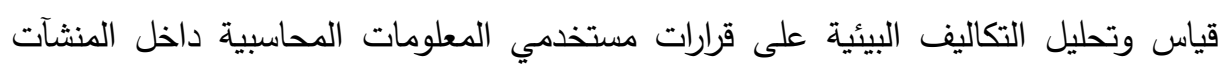
الصناعية، المعوقات التي تواجه المنشآت الصناعية في قياس وتحليل التكاليف البيئية، بيان أهمية قياس وتحليل التكاليف البيئية داخل المنشآت الصناعية. 
دراسة مهاوات لعبيدي (؟ ا ب): بعنوان: القياس المحاسبي للتكاليف البيئية والافصاح عنها في القوائم المالية لتحسين الأداء البيئي - دراسة حالة مجموعة من المؤسسات الصناعية الصيات في الجزائر .

أهداف الاراسة: الافصاح عن التكاليف البيئية في التقارير المالية لتحسين الأداء البيئي،

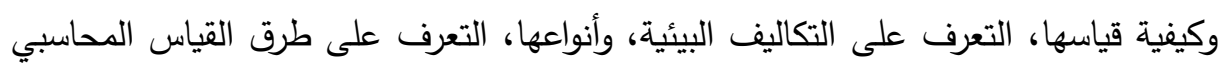
للتكاليف البيئية، والمعوقات التي تعترض تطبيقها فئها في المؤسسات الصناعية، التعرف على طرق ومؤشرات تحسين وتقييم الأداء البيئي.

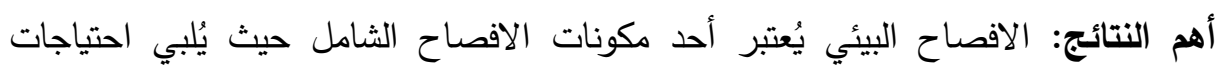

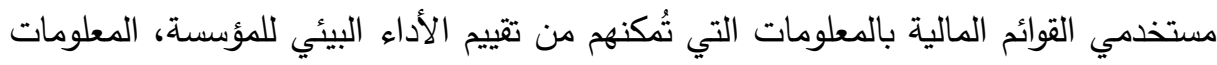

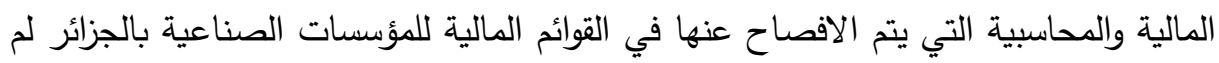
تُشير لأي من الآثار المالية نتيجة لأدائها (عمليات أو أنثطة بيئية)، ولو في شكل تقارير لئيل مفصلة. دراسة (Nasreldeen Gidam Elnagy, 2014): بعنوان: القياس والافصاح عن جودة التكاليف البيئية وأثرها على القوائم المالية المنشورة. أهداف الدراسة: بيان دور القياس والافصاح البيئي في جودة المعلومات المحاسبية، اقتراح نموذج للافصاح وقياس وتحليل تكاليف الجودة البيئية تظهر نتائجها على القوائم المالية.

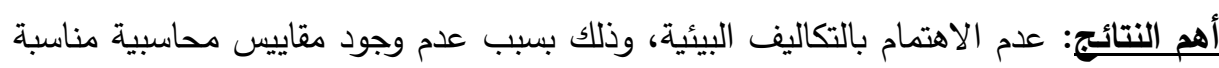
لقياس تكاليف الجودة البيئية على الأنثطة الصناعية. دراسة (Florence, et al., 2016): بعنوان: أثر تعريف التكاليف البيئية على جودة

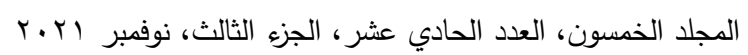

$$
\begin{aligned}
& \text { الترقيم الدولي 0826-0 الترني } \\
& \text { الترقيم الدولي الموحد الإكتروني 3178-2636 لأن }
\end{aligned}
$$


أهداف الدراسة: بيان أثر القياس والافصاح البيئي على جودة المعلومات المحاسبية، ووجود تأثير لتحديد التكاليف البيئية على جودة الافصاح. لئن أهم النتائج: وجود تأثير لتحديد التكاليف البيئية على جودة الافصاح، تضمين التياح التكاليف البيئية عند تقدير النفقات أو التكاليف المتعلقة بالشركة.

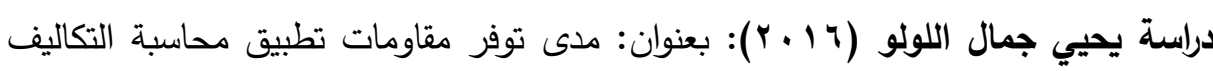
البيئية في الثركات الصناعية العاملة فى قطاع غزة - دراسة ميدانية تحليلية. أهداف الاراسة: التعرف على محاسبة التكاليف البيئية، والدور الذى تقوم به فئ فى تقليل المشكلات البيئية، توضيح مستوى الوعى البيئي لدى الادارة العلدا، ومدى التزامها تجاه البيئة،

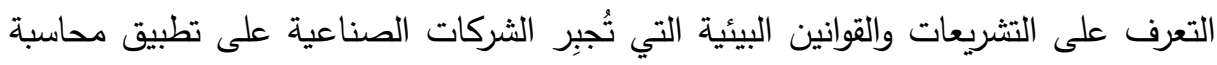
التكاليف البيئية، التعرف على مدى توفر مقومات تطبيق محاسبة التكاليف البيئية فى الشركات الصناعية العاملة فى قطاع غزة. أهم النتائج: انخفاض مستوى الوعى البيئي الادارة العلدا داخل الشركات الصناعية بمعرفة المزايا والفوائد التى تتحقق من تطبيق محاسبة التكاليف البيئية، عدم توفر الوعى البيئى اللازم لاى الادارة العلنا داخل الثركات الصناعية لتطبيق محاسبة التكاليف البيئية، مستوى التزام الادارة العلنا داخل الثركات الصناعية تجاه البيئة غير كافى لتطبيق محاسبة التكاليف البيئية. دراسة عادل حسين على (Y V V Y): بعنوان: التكاليف البيئية، ودورها في تحسين المعلومات المحاسبية المُقدمة لاتخاذ القرارات - دراسة ميدانية في الثركات الصناعية - الانبار .

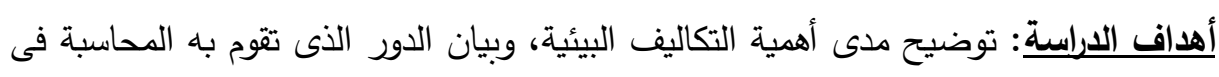

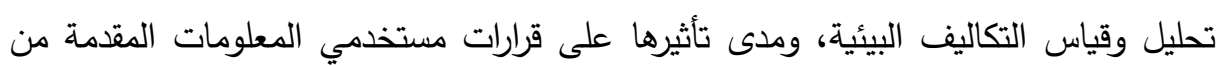
النظام المحاسبي.

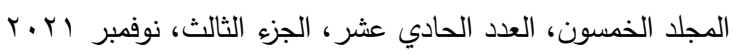

$$
\begin{aligned}
& \text { الترقيم الدولي 0826-08S 1110 } \\
& \text { الترقيم الدولي الموحد الإكتروني 3178-2636 }
\end{aligned}
$$


أهم النتائج: صعوبة قياس وفصل التكاليف البيئية عن التكاليف الاجمالية، لا يوجد تطبيق للتكاليف البيئية، وذلك نظرا لعدم توافر الكوادر البشرية المؤهلة للاهتمام بتلك التكاليف. دراسة ضياء الدين (Y V † Y): بعنوان: دور المراجعة الخارجية في تحسين جودة القوائم المالية - دراسة لعينة من محافظي الحسابات وبعض المؤسسات بولاية ورقلة.

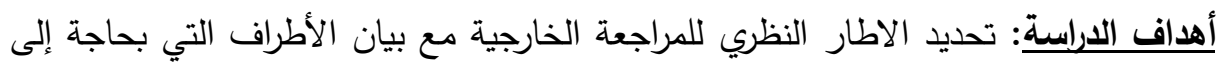
هذا النوع من المراجعة، بيان الدور الذي تلعبه عملية المراجعة في المساعدة على تقديم قوائم

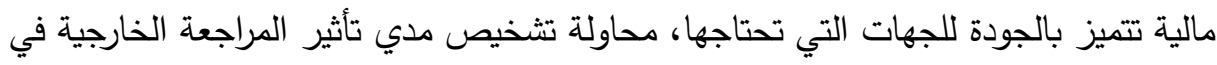
جودة القوائم المالية.

أهم النتائج: المراجعة الخارجية تُعتبر وظيفة تتم عن طريق مراجع خارجي مُستقل عن

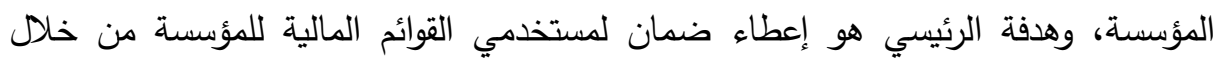

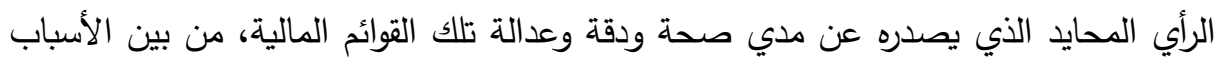
التي تحد من الالتزام بتطبيق إرشادات المراجع الخارجي، وضعف الهتمام الإدارة بتقارير

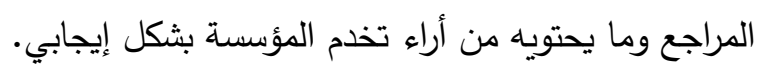

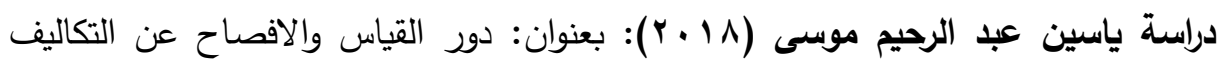

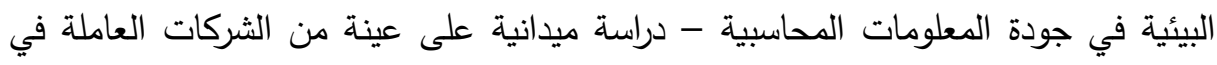
السودان. أهداف الدراسية: بيان أثر قياس التكاليف البيئية على موثوقية المعلومات المحاسبية، التعرف على العلاقة بين قياس التكاليف البيئية وقابلية المعلومات المحاسبية للفهم والمقارنة، اختبار العلاقة بين قياس التكاليف البيئية والافصاح عنها وجودة المعلومات المحاسبية.

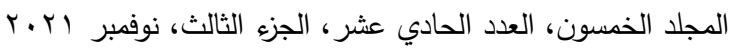

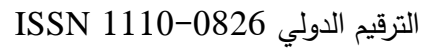

$$
\begin{aligned}
& \text { الترقيم الدولي الموحد الإكتروني 3178-2636 لأن }
\end{aligned}
$$


أهم النتائج: قياس التكاليف البيئية والافصاح عنها يسهُم في إتاحة القوائم والتقارير المالية للمعلومات الكافية لاتخاذ القرارات، ووجود ارتباط بين قياس التكاليف البيئية وعدالة القوائم المالية، قياس التكاليف البيئية بالشركات يسهم في تعزيز ثقة مستخدمي المعلومات المحاسبية.

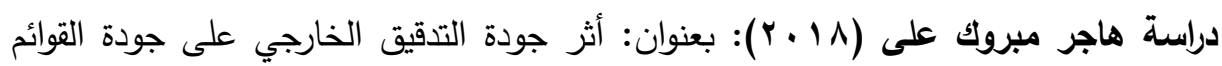
المالية في ظل الافصاح.

أهداف الارلسة: التعرف على أثر جودة التدقيق الخارجي على جودة القوائم المالية وطريقة تحسينها، توضيح الدور الذي يؤديه التدقيق الخارجي في تحقيق جودة القوائم المالية، تقديم

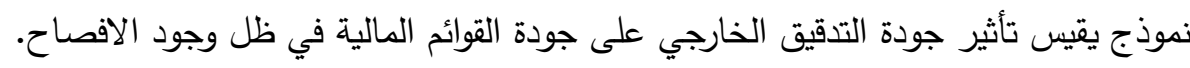

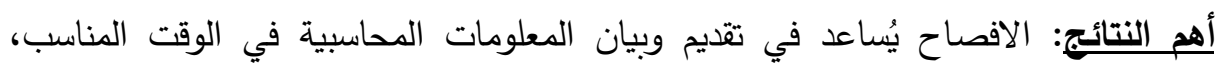

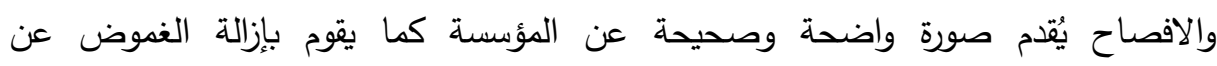

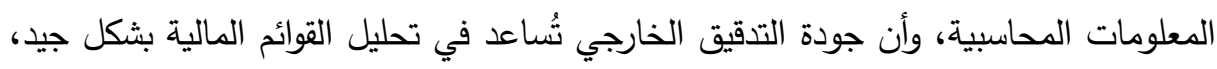
وبالتالي اتخاذ قرارات اقتصادية صحيحة.

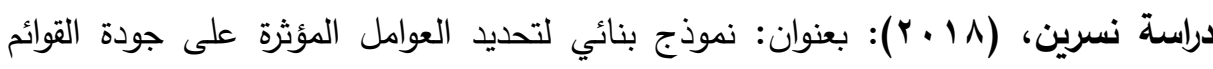

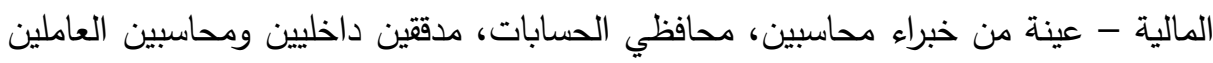
في أم البواقي. - ماله

أهداف الدراسة: تحديد أثر النظام المحاسبي عند إعداد القوائم المالية، أثر التدقيق المحاسبي على جودة القوائم المالية وضمان صحتها وجودتها ومدي موضوعية هذه القوائم التي تدققها لجان التدقيق، وضع نموذج بنائي يقيم حجم أثر مختلف العوامل المؤثرة على جودة القوائم

أهم النتائج: الافصاح عبارة عن عملية تقديم معلومات وإظهارها في الوقت المناسب لإعطاء صورة واضحة وصحيحة عن المؤسسة، وزيادة الثقة في القوائم المالية، يهدف إلي إزالة 160

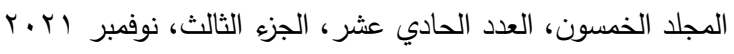

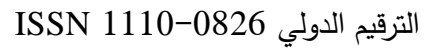

$$
\begin{aligned}
& \text { الترقيم الدولي الموحد الإكتروني 3178-2636 لكرلي }
\end{aligned}
$$


الغوض في عرض المعلومات، إدارة الأرباح تُعتبر سلوك تقوم به الادارة ويؤثر في الدخل الذي يظهر في القوائم المالية، كما تهدف في خلق انطباع مختلف عن الحقيقة، التدقيق الداخلي يعتبر من أهم الوظائف التي ترتكز علدها المؤسسة وهو نشاط تقويمي لكافة الأنثطة والعمليات لمساعدة الادارة في تقييم وتحسين الفعالية وتهدف لجان التدقيق للتأكد من موثوقية ومصداقية القوائم المالية.

\section{الإسار اللنظليه}

ماهية التكاليف البيئية: تعددت تعريفات التكاليف البيئية على النحو التالي:

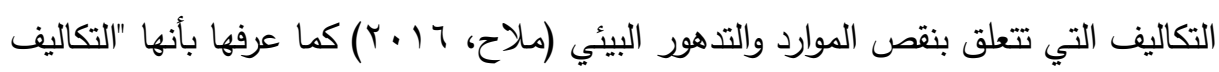
التي يصعب قياسها كمياً بسبب طبيعتها الغير ملموسة، ويتم تحميلها في حسابات النفقات العامة والادارية وهي تعود إلي المنتجات أوالعمليات أو الأنثطة المسئولة عن إنشائها"

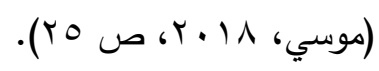

كما عرفت بأنها عبارة عن مقياس لازالة الضرر الذي يصيب المجتمع نتيجة ممارسة

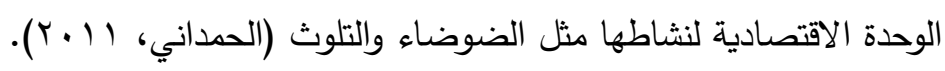
والتكاليف البيئية تتضمن تكاليف الاجراءات التي يتم اتخاذها لادارة الآثار البيئية التي

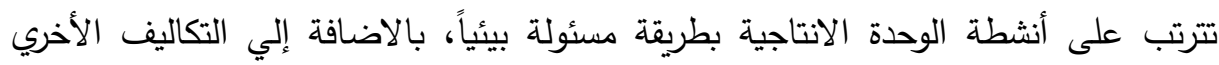

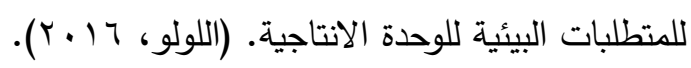

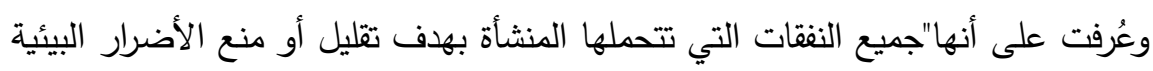

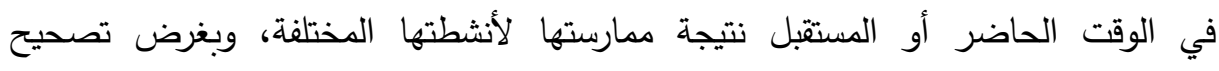

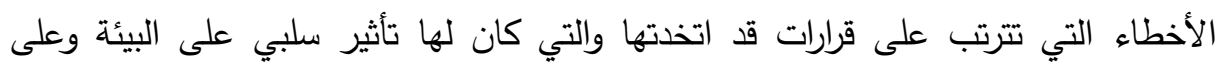

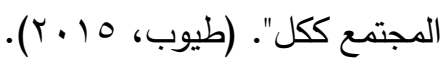

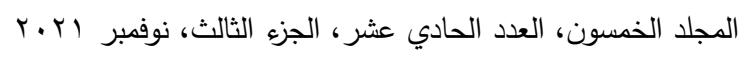

$$
\begin{aligned}
& \text { الترقيم الدولي 0826-0 الترني } \\
& \text { الترقيم الدولي الموحد الإكتروني 3178-2636 }
\end{aligned}
$$


خصائص التكاليف البيئية (حنان، ب ـ ب):

ا ـ العمل على توفير المعلومات المادية التي تُعبر عن قيمة التلوث البيئي، ومدى تأثيره على

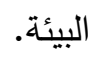

r. بعضها غير قابل للقياس، وذلك نظراً لعدم تداولها في الأسواق.

r. المؤسسات هي التي تتجنب عبء تكاليف تقليل الأضرار البيئية، وذلك لصعوبة تقديرها. ع. تُحدد موقع المؤسسات الصناعية، والعمل على ترشيد القرارات المتعلقة باقتناء الآلات

والمعدات التشغيلية.

ه. تُككِن المؤسسات الصناعية من تحديد الأنشطة والعمليات التي ينتج عنها تكاليف، مما

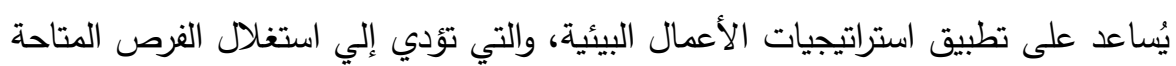

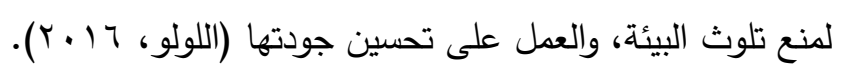

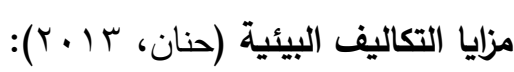

ا ـ التكاليف البيئية تُساعد على رفع كفاءة النظام المُطبق لمحاسبة التكاليف، وترشيد القرارات

التشغيلية.

r. تعمل التكاليف البيئية على رفع كفاءة آداء المؤسسات الصناعية، وتحسين جودة البيئة. r. تسعي المؤسسات على تصحيح جوانب القصور فيها والعمل على تطويرها وذلك نظراً لاهتمام التكاليف البيئية بأساليب الادارة البيئية.

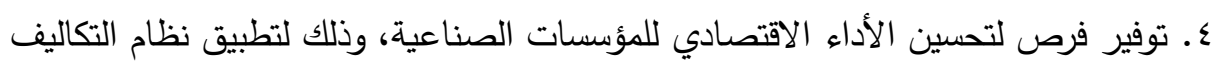

البيئية.

ه. تطبيق أساليب التكاليف البيئية داخل المؤسسات الصناعية تُساعدها على زيادة الأرباح والاستخدام الأمثل للموارد وزيادة الاهتمام بالبيئة وحمايتها واتخاذ القرارات المُّثلي في مجال الأداء البيئي.

162

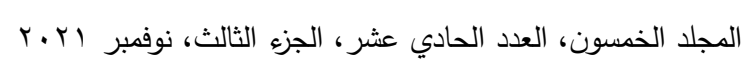

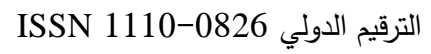

$$
\begin{aligned}
& \text { الترقيم الدولي الموحد الإكتروني 3178-2636 }
\end{aligned}
$$


7. تعتبر التكاليف البيئية حافزاً لتوجيه المؤسات نحو الالتزام البيئي وأخذ البيئة بعين

$$
\begin{aligned}
& \text { الاعتبار في تقييم المشاريع. }
\end{aligned}
$$

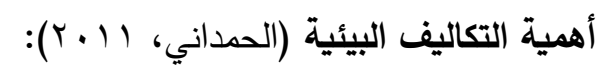

أ. تُعتبر المقابلة التي تتم بين التكاليف والايرادات غير سليمة دون الأخذ في الاعتبار التكاليف البيئية لأن الوعاء الخاضع للضريبة والأرباح لم تتحدد بشكل سليم، ولكي يتم

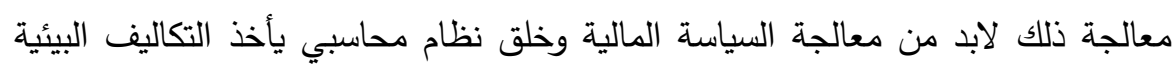
بعين الاعتبار عند إجراء تلك المقابلة.

ب.تتضمن القوائم المالية معلومات عن التكاليف البيئية سوف تُساهم في تطوير وتحسين

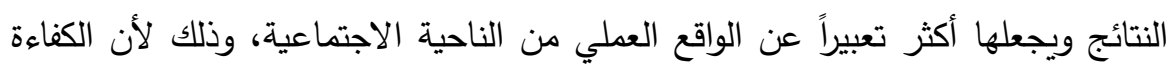

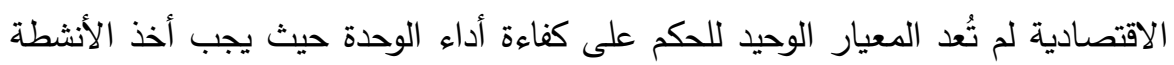

$$
\text { البيئية بعين الاعتبار . }
$$

ماهية القوائم المالية: وأنها عبارة عن "هجموعة من الوثائق المحاسبية التي تهفف إلي إعطاء صورة صادقة عن المركز المالي للمؤسسة وسيولة الخزينة في نهاية السنة، فالقوائم

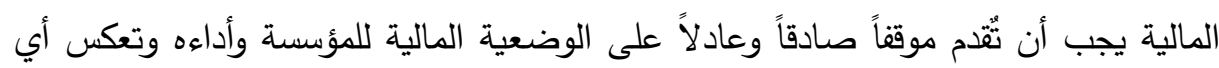
تغيير في مركزه المالي نتيجة المعاملة والآثار المترتبة عنها، كما أن المعلومات الوفاتهات الواردة في

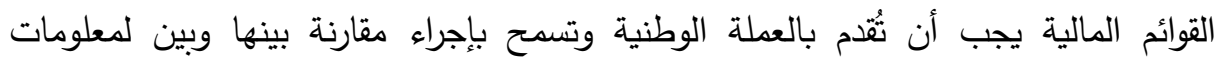

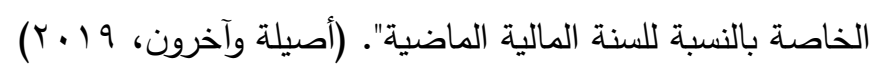
عُرفت القوائم المالية بأنها مجموعة كاملة من الحسابات تثتمل على الميزانية، قائمة تدفقات الخزينة، قائمة تغير الأموال الخاصة، قائمة حساب النتيجة، والهدف من هذه التهات القوائم

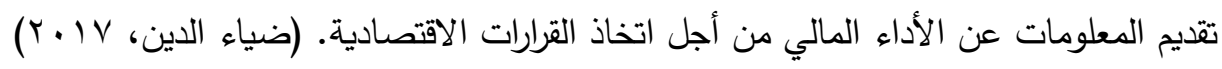

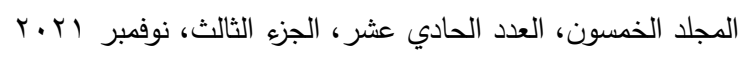

$$
\begin{aligned}
& \text { الترقيم الدولي 0826-0 الترني } \\
& \text { الترقيم الدولي الموحد الإكتروني 3178-2636 }
\end{aligned}
$$


عُرفت على أنها وسائل رئيسية لتوصيل المعلومات المحاسبية إلي الأطراف الخارجية، بالرغم من أن القوائم المالية قد تحتوي على معلومات من مصادر خارج السجلات المحاسبية، إلا أن النظم المحاسبية مُصممة بثكل عام على أساس عناصر القوائم المن المالية (منانه، . ( $.1 \leq$

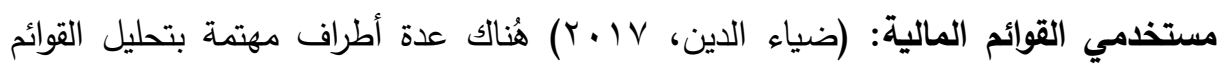
المالية، كما تتنوع أغراض استخدامها لتلك المعلومات وذلك وفقاً لتتوع علاقاتهم بالمؤسسة،

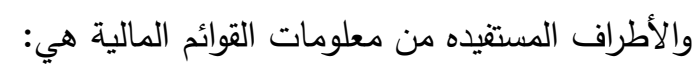
ا ـ العاملون: يهتم العاملون بالمعلومات التي تتعلق بربحية واستقرار المؤسسة من أجل معرفة

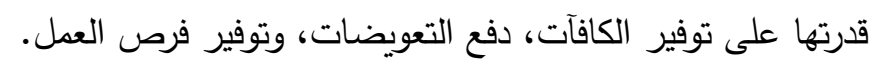
r. الدائنين: يهتم الدائنين بالمعلومات التي تتعلق بالقدرة على السداد وآجال الاستحقاق.

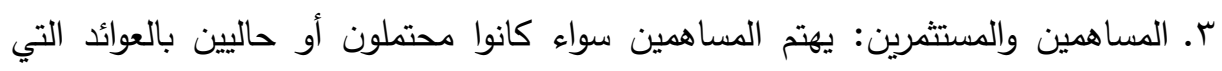

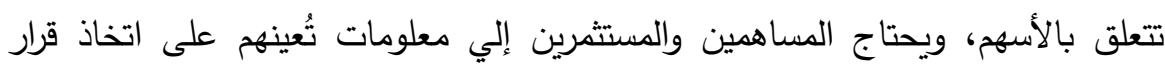

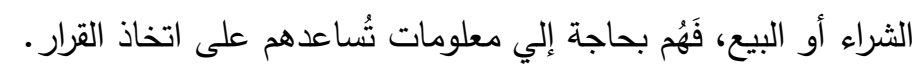

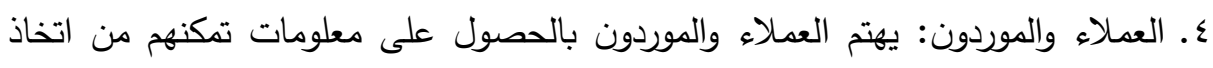

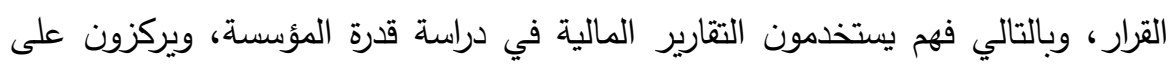
تلك المعلومات بدرجة أكبر عند وجود تعاملات طويلة الأجل.

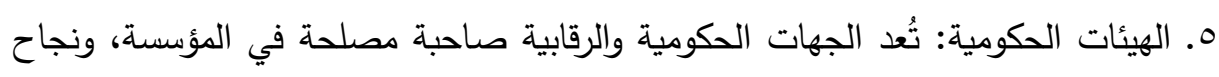
معدلات أدائها الاقتصادي المرتفع، وبالتالي تضمن الجهات قدرة على سداد الضرائب بانتظام.

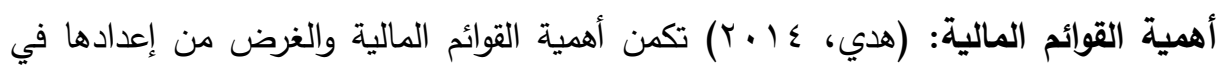
ثلاث نقاط، ويمكن تلخيصها كالتالي: 164

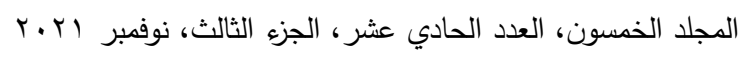

$$
\begin{aligned}
& \text { الترقيم الدولي 0826- ISSN 1110 } \\
& \text { الترقيم الدولي الموحد الإكتروني 3178-2636 }
\end{aligned}
$$


• وسيلة تُساعد في اتخاذ القرارات، أداة اتصال، ووسيلة في تقييم الأداء.

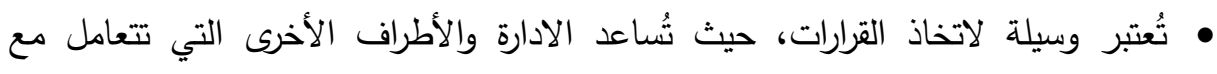

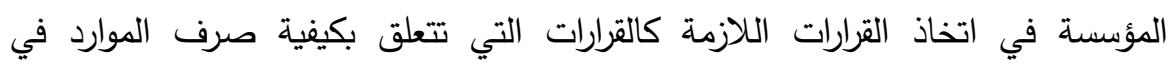

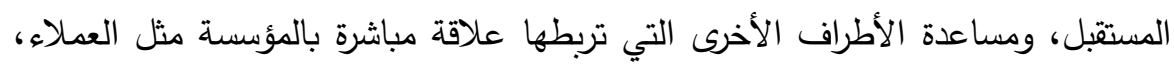

$$
\text { والموردين والبنوك في توجيه العلاقات المستقبلية معها. }
$$

• تعتبر القوائم المالية همزة وصل بين المؤسسة والمستثمرين فيها، ووسيلة لتوفير المعلومات ولئه

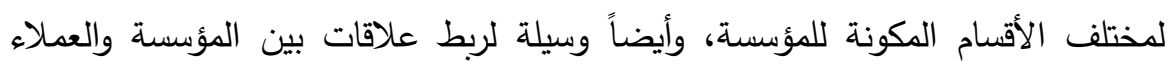
والموردين، والبنوك. وأيضاً تُعتبر وسيلة لتقييم أداء الادارة والحكم على كفاءتها واستعمال الموارد الموضوعة تحت تصرفها فتستعمل في الحكم على المركز المالي للمؤسسة، ومدي ولي ولئي التقدم في تحقيق أهداف المؤسسة، وأيضاً كيفية استخدام موارد المؤسسة.

\section{إلجاءائش المهمث}

وصف مجتمع وعينة الدراسة: يتمثل مجتمع الدراسة في مجموعة من الثركات القابضة للصناعات الدوائية وهي عبارة عن V شركات هي (شركة مدفيس للأدوية والصناعات الكيماوية - شركة القاهرة للأدوية والصناعات الكيماوية - الثركة العربية للأدوية - شركة تتمية الصناعات الكيماوية"سيد"- شركة النيل للأدوية والصناعات الكيماوية - شركة هولدي فارما للتسويق والتصدير - الشركة المتحدة للكيماويات والمستلزمات الطبية) ونظراً لصعوبة لصنية

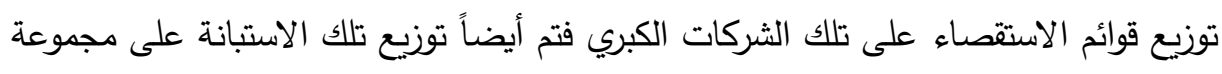

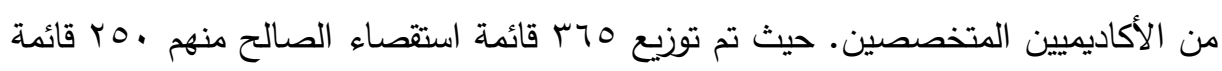
وتم عمل التحليل الاحصائي لهم.

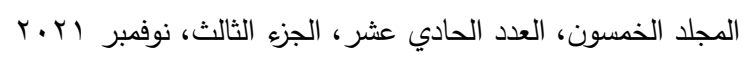

$$
\begin{aligned}
& \text { الترقيم الدولي } \\
& \text { الترقيم الدولي الموحد الإكتروني 3178-2636 }
\end{aligned}
$$


لقد تم توزيع استمارات الإستقصاء على عينة عشوائية من موظفي الشركات القابضة

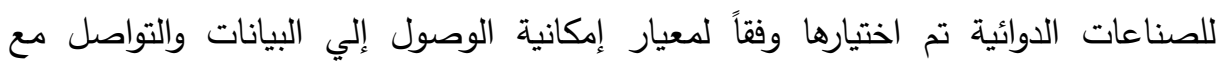
مفردات العينة، فتم توزيع عدد من الاستبانات على المحاسبين والمحلين الماليين بشركة

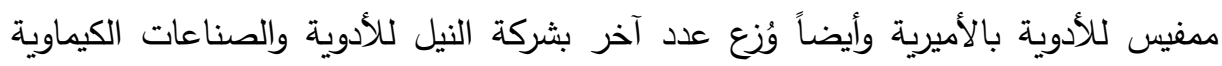

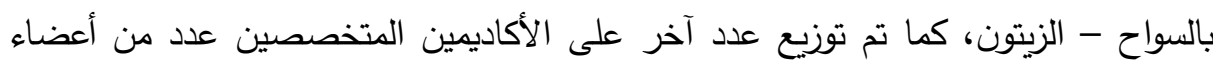
هيئة التدريس والهيئة المعاونة بجامعتي طنطا، والسادات. أداة الاراسة : قائمة الاستقصاء حيث أنها الأداة الملائمة لطبيعة الدراسة. محتويات أداة الاراسة: تتكون القائمة من ثلاث محاور رئيسية وهي: المحور الأول: أثر التكاليف البيئية على جودة القوائم المالية وقيمة المنثأة ويتضمن من الثئية وهئ الأسئلة 1-يشير ارتفاع التكاليف البيئية إلي إهتمام المنشأة بالحفاظ على البيئة. r-يؤدي ارتفاع الوعي البيئي في المنشآت إلي زيادة التكاليف البيئية. ب-زيادة التكاليف البيئية يسهم في زيادة جودة القوائم المالية. ع-يؤدي الافصاح الاضافي عن التكاليف البيئية والاجتماعية إلي زيادة جودة القوائم المالية وقيمة المنثأة. 0-يسهم قيام المنشآت بمسئولياتها البيئية والاجتماعية في التتمية المستدامة للمنشأة. צ-تؤدي صعوبات قياس التكاليف البيئية إلي التأثير على جودة القوائم المالية. V-تزيد قوة أثر قيام المنثأة بالتزاماتها البيئية عندما يرتفع الوعي البيئي لدي الدي المستثمرين في سوق الأوراق المالية. ^-تطبيق نظام التكاليف البيئية في المؤسسات الصناعية يتطلب تكلفة عالية لإعداد الاداريين

$$
\text { والعمال والتعاملات مع الأطراف الأخري. }
$$


9- القياس والافصاح عن التكاليف البيئية في القوائم المالية في المؤسسات الصناعية يتطلب وجود جهات تشريعية مهنية مستقلة تعمل على تتظيم محاسبة التكاليف البيئية وإصدار تشريعات ملزمة بتطبيقها.

• 1-عملية القياس والافصاح المحاسبي للتكاليف البيئية في قطاع صناعة الأدوية تؤدي إلي تلبية احتياجات المستهلكين للمنتجات الصديقة للبيئة وبمعايير الجودة البيئة المناسبة. 11- الافصاح عن التكاليف البيئية في القوائم المالية يُسبب الإساءة لسُمعة المؤسسات

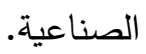

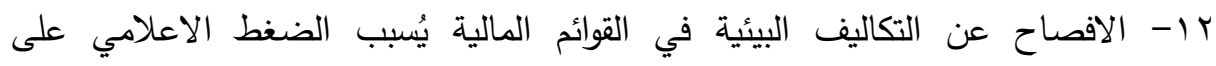
المؤسسات الصناعية بسبب الأضرار البيئية.

rا - الافصاح عن التكاليف البيئية في القوائم المالية يؤدي إلي زيادة أعباء المؤسسات الصناعية في الحصول على استثمارات مالية إضافية لحماية البيئة.

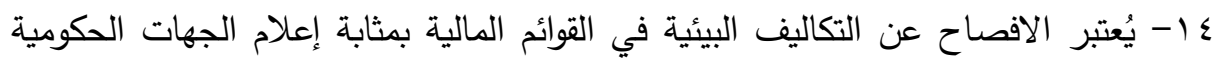
والأهلية بالأضرار البيئية الناتجة عن المؤسسات الصناعية. 10- تعمل إدارة المؤسسات الصناعية على تطوير أنظمة المعلومات الحالية للتكيف ومجاراة المتطلبات التقنية والفنية لتطبيق نظام محاسبة التكاليف البيئية. 7 ا 1 - إن نظام التكاليف الحالي المُطبق في المؤسسات الصناعية لا يعمل على حل كافة المشاكل التي تواجه القياس والافصاح عن التكاليف البيئية. المحور الثاني: أثر المنافع البيئية على جودة القوائم المالية ويتضمن الأسئلة التالية:

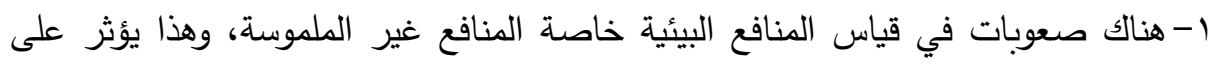
جودة القوائم المالية.

r- هُناك علاقة قوية بين قياس المنافع البيئية، وجودة القوائم المالية.

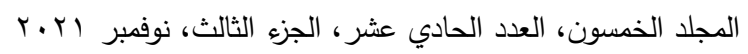

$$
\begin{aligned}
& \text { الترقيم الدولي 0826-08S 1110 } \\
& \text { الترقيم الدولي الموحد الإلكتروني 3178-0826-2636 }
\end{aligned}
$$


ب-يتطلب قياس المنافع البيئية تحديد الأنشطة البيئية بدقة، ومردودها الايجابي. ع-يرتبط قياس المنافع البيئية ودورها في جودة القوائم المالية زيادة الوعي البيئي لدي المستثمرين.

ه-يرتبط القياس المحاسبي للمنافع البيئية بتطوير سجلات محاسبية تُساعد في ذلك. ج-يرتبط الافصاح عن التكاليف والمنافع البيئية بوجود مجموعة من المبادئ والسياسات المحاسبية المرتبطة بطبيعة الثركات الملوثة للبيئة.

V- يُعتبر الافصاح عن المنافع البيئية الملموسة وغير الملموسة بمثابة تحسين لسُمعة المنشأة، ودورها في التتمية المستدامة.

المحور الثالث: العلاقة بين قياس التكاليف والمنافع وكفاءة الأداء ويتضمن الأسئلة التالية: ا-هُناك ارتباط هام بين قياس التكاليف والمنافع البيئية، وأداء الثركة. ץ-تزداد أهمية تقييم أداء الثركات في مجال البيئة إذا كانت تعمل في قطاعات ملوثة للبيئة

$$
\text { مثل قطاع الأدوية. }
$$

ب-يجب إلزام شركات الأدوية بالقيام بمسئولياتها البيئية والاجتماعية. ع-يرتبط تقييم أداء شركات الأدوية في مجال البيئة بوجود مؤشرات ونسب مالية واضحة لقياس الأداء البيئي. ه-يزيد قياس الأداء البيئي في شركات الأدوية من قدرة المستثمرين على التتبؤ بالتدفقات التئس النقدية المستقبلية للثركة. ج-ترتبط اتجاهات الربحية والتتمية المستدامة في شركات الأدوية بمدي التزام الثركة بالجانب البيئي. V-يُفضل إعداد تقارير مالية مستقلة للأداء البيئي (المنافع والتكاليف). 
^-يُفضل إعداد تقارير مالية متكاملة تشمل الأداء المالي والاقتصادي من ناحية والأداء

$$
\text { البيئي والاجتماعي من ناحية أخري. }
$$

مقاييس أداة الدراسة: حيث يُرمز لكل عبارة برقم يدل على إجابة الثخص إخص

\begin{tabular}{|c|c|}
\hline غير موافق بشدة & 1 \\
\hline غير موافق & r \\
\hline محايد & r \\
\hline موافق م & $\varepsilon$ \\
\hline موافق بشدة & 0 \\
\hline
\end{tabular}

طريقة العرض: تم توزيع الاستبيان الكترونياً لأنه الوسيلة الأسرع في الوقت والجهد حيث تم

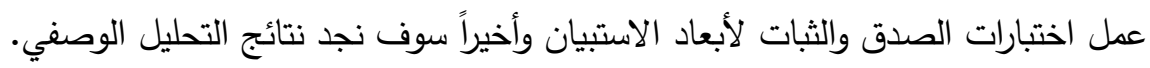

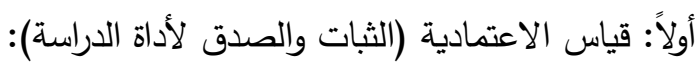
ثبات الاستبيان: للتحقق من ثبات أدوات الدراسة لإمكانية الاعتماد على نتائجها استخدمت الأدان الباحثة معادلة ألفا كرونباخ (Alpha Cronbach)، ويوضح الجدول التالي معاملات الثبات لاتل الناتجة باستخدام هذه المعادلة. جدول (1): بات العبارات لأبعاد الاستبيان

\begin{tabular}{|c|c|c|}
\hline قيمة ألفا & عدد العبارات & أبعاد الاستبيان \\
\hline$\cdot, 0 \wedge 7$ & 17 & أثثر التكاليف البيئية على جودة القوائح المالية وقيمة المنشاة \\
\hline., 094 & $\Lambda$ & العلاقة بين قياس التكاليف وكفاءة الأداء \\
\hline$\cdot, 709$ & $\overline{T \varepsilon}$ & إجمالى الاستبيان \\
\hline
\end{tabular}

يتضح من الجدول السابق أن معاملات الثبات قيم مرتفعة حيث بلغت قيم معامل الثبات

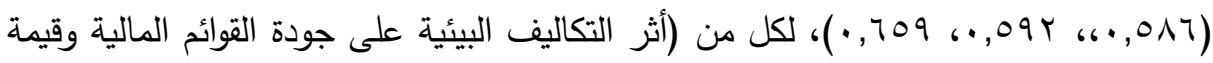

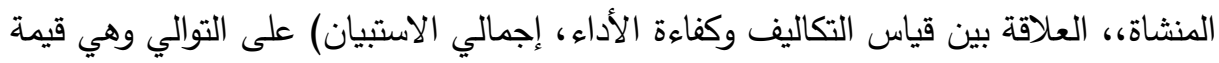

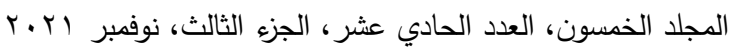

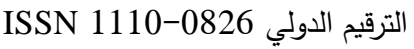

$$
\begin{aligned}
& \text { الترقيم الدولي الموحد الإلكتروني 3178-0826-2636 }
\end{aligned}
$$


مقبولة، تثير هذه القيم من معاملات الثبات إلى صلاحية العبارات وإمكانية الاعتماد على نتائجها والوثوق بها. الإحصاء الوصفي: بعد إفراغ الاستبيانات في برنامج ال SPSS، واستخراج النتائج الوصفية

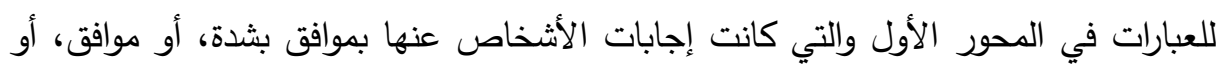
محايد، أو غير موافق، أو غير موافق بثدة.

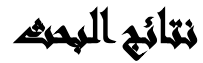

جدول (ץ): الاحصاء الوصفي لعبارات أثر التكاليف البيئية على جودة القوائم المالية وقيمة المنشاة

\begin{tabular}{|c|c|c|c|c|c|c|c|c|c|c|}
\hline \multicolumn{2}{|c|}{ غيثدة موافق } & \multicolumn{2}{|c|}{ غير موافق } & \multicolumn{2}{|c|}{ محايد } & \multicolumn{2}{|c|}{ موافق } & \multicolumn{2}{|c|}{ موافق بشدة } & \multirow{2}{*}{ العبارات } \\
\hline$\%$ & S & $\%$ & ك & $\%$ & ك & $\%$ & S & $\%$ & S & \\
\hline 1,7 & $\varepsilon$ & 1,7 & $\varepsilon$ & 1,7 & $\varepsilon$ & $r$ & 100 & $r r, r$ & $\Lambda \mu$ & 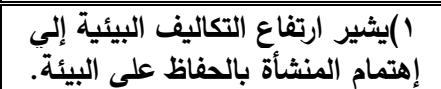 \\
\hline$r \cdot, \varepsilon$ & 01 & - & - & $r \wedge, \wedge$ & $9 \mathrm{~V}$ & $|r \wedge, \xi|$ & $v_{1}$ & $\mid r, \varepsilon$ & ri & المنشآت إلى زبيادة التكاليف البئي فيئية. \\
\hline $0, Y$ & 14 & $\Lambda, \varepsilon$ & r & 79,5 & $|\vee V r|$ & 7,1 & iv & $1 \cdot, \varepsilon$ & Y & 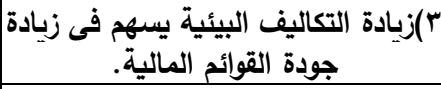 \\
\hline 1,7 & $\varepsilon$ & . & . & 9,7 & $r \varepsilon$ & 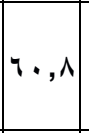 & $10 \%$ & 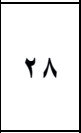 & v. & 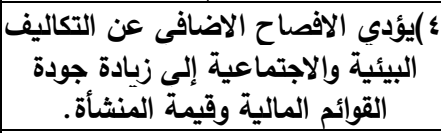 \\
\hline 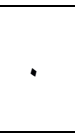 & . & . & . & · & . & 09,7 & $1 \leqslant 9$ & $\{\bullet, \varepsilon$ & 1.1 & 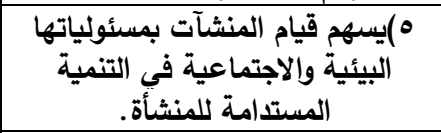 \\
\hline · & . & r & • & $1 \%, \Lambda$ & $r r$ & $\bullet V, r$ & $1 \leqslant r$ & rA & v. & البئية إلّي التأثير على جياس جودة التكاليف \\
\hline
\end{tabular}

170

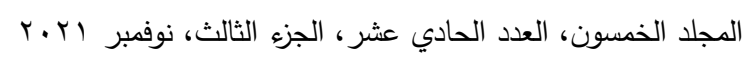
الترقيم الدولي 0826- ISSN 1110 الترقيم الدولي الموحد الإكتروني 3178-2636 
مجلة العلوم البيئية

كلية الدراسات العلنا والبحوث البيئية - جامعة عين شمس لبيه

دعاء محمود حرحش وآخرون

\begin{tabular}{|c|c|c|c|c|c|c|c|c|c|c|}
\hline \multicolumn{2}{|c|}{ غير موافق بثدة } & \multicolumn{2}{|c|}{ غير موافق } & \multicolumn{2}{|c|}{ محايد } & \multicolumn{2}{|c|}{ موافق } & \multicolumn{2}{|c|}{ موافق بثدة } & \multirow[t]{2}{*}{ العبارات } \\
\hline$\%$ & ك & $\%$ & ك5 & $\%$ & ك & $\%$ & ك & $\%$ & ك & \\
\hline - & - & • & - & $\leqslant 7, \wedge$ & $11 \mathrm{~V}$ & $r \wedge, \varepsilon$ & 97 & $1 \varepsilon, \wedge$ & $r v$ & 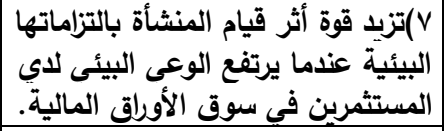 \\
\hline - & • & Ir & $r \cdot$ & $\because \wedge, \wedge$ & IVY & $1 \varepsilon$ & ro & $0, r$ & 14 & 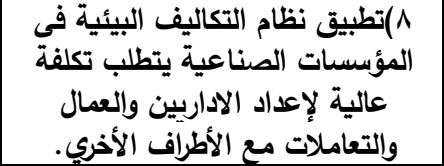 \\
\hline - & • & 7,1 & IV & $\mid r, r$ & $r r$ & $V \varepsilon, \varepsilon$ & $1 \wedge 7$ & 0,7 & $1 \leqslant$ & 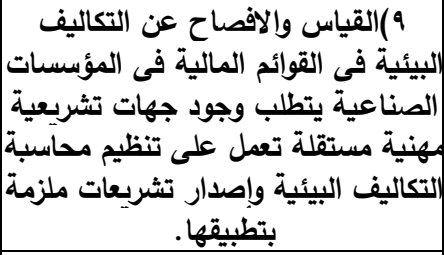 \\
\hline - & • & • & • & $19, Y$ & $\leqslant 1$ & $74, \wedge$ & 178 & $1 \varepsilon$ & ro & 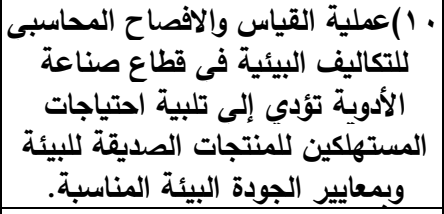 \\
\hline • & - & 17,1 & $\varepsilon r$ & $v \cdot, \varepsilon$ & 187 & $\wedge, \wedge$ & rr & $\varepsilon$ & 1. & 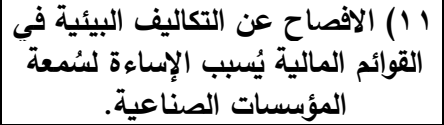 \\
\hline$\varepsilon, \wedge$ & Ir & r 1,7 & $0 \leq$ & 00,7 & 119 & $1,, \varepsilon$ & rq & $v, q$ & 19 & 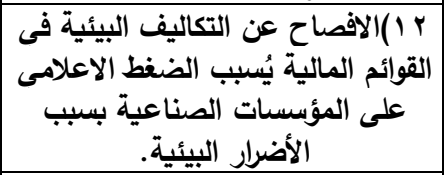 \\
\hline 1,7 & $\varepsilon$ & rᄉ & 90 & $r 1, r$ & $\vee \wedge$ & $I V, Y$ & $\varepsilon r$ & ir & $r$. & 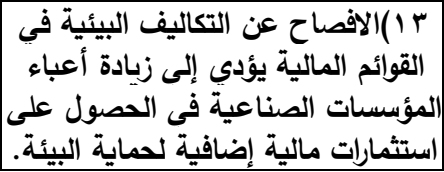 \\
\hline
\end{tabular}

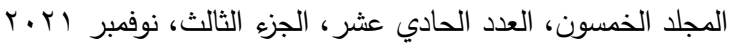

الترقيم الدولي 0826-0 تصني

الترقيم الدولي الموحد الإكتروني 3178-2636 
مجلة العلوم البيئية

كلية الدراسات العلنا والبحوث البيئية - جامعة عين شمس لئه

دعاء محمود حرحش وآخرون

\begin{tabular}{|c|c|c|c|c|c|c|c|c|c|c|}
\hline \multicolumn{2}{|c|}{ غير موافق } & \multicolumn{2}{|c|}{ غير موافق } & \multicolumn{2}{|c|}{ محايد } & \multicolumn{2}{|c|}{ موافق } & \multicolumn{2}{|c|}{ موافق بشدة } & \multirow[t]{2}{*}{ العبارات } \\
\hline$\%$ & ك5 & $\%$ & ك & $\%$ & ك5 & $\%$ & ك & $\%$ & ك & \\
\hline$V, r$ & 11 & $\varepsilon, \wedge$ & ir & $\mid r, \lambda$ & rr & $0 \wedge, \leqslant$ & $1 \leq 7$ & 18,1 & $\leqslant r$ & 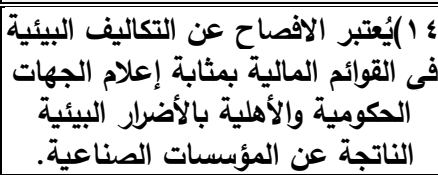 \\
\hline 1,7 & $\varepsilon$ & 7,1 & IV & 1,7 & $\varepsilon$ & v. & ivo & $r$. & 0. & 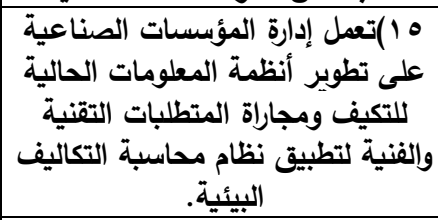 \\
\hline . & · & - & - & 1. & ro & Yq, ४ & $V \leqslant$ & $7 ., 8$ & 101 & 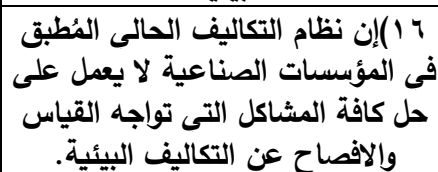 \\
\hline
\end{tabular}

يتضح من جدول (Y) أن Y0,Y\% من الأشخاص موافقون على أنه يرجع ارتفاع

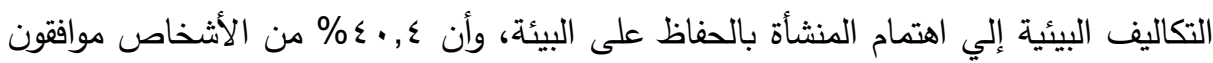

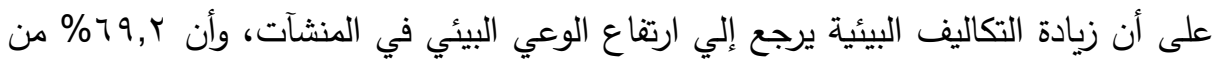

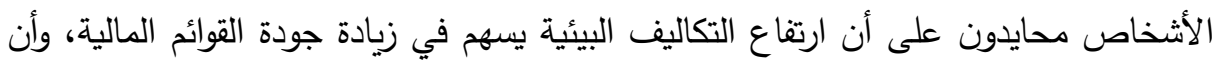

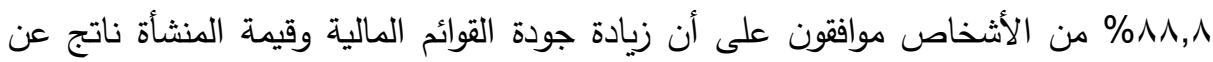

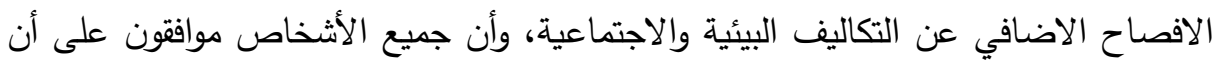
قيام المنثآت بمسئولياتها البيئية والاجتماعية يسهم في التتمية المستدامة للمنشأة، وأن

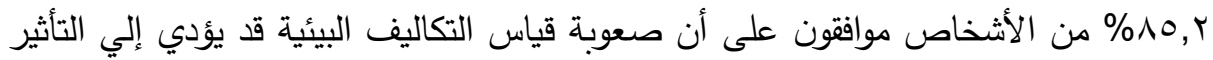

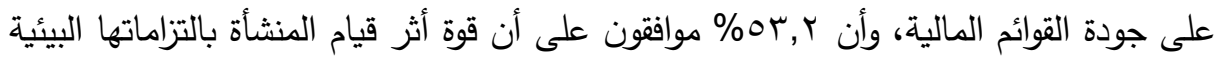

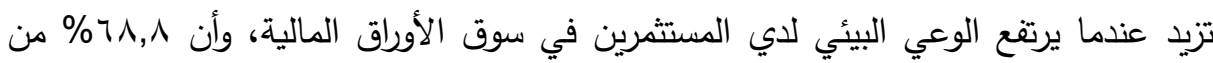

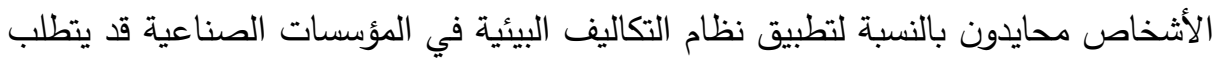

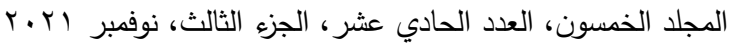

$$
\begin{aligned}
& \text { الترقيم الدولي 0826-110 تصدون } \\
& \text { الترقيم الدولي الموحد الإكتروني 3178-2636 }
\end{aligned}
$$


تكلفة عالية لإعداد الاداريين والعمال والتعاملات مع الأطراف الأخري، وأن •^٪ من الأشخاص موافقون على أن عملية القياس والافصاح عن التكاليف البيئية في القوائم المالية داخل المؤسسات الصناعية تتطلب وجود جهات تشريعية مهنية مستقلة تعمل على تتظيم

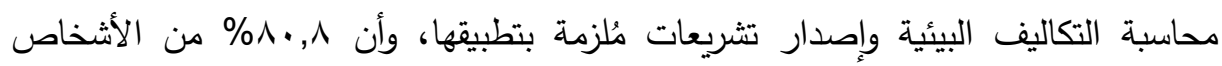

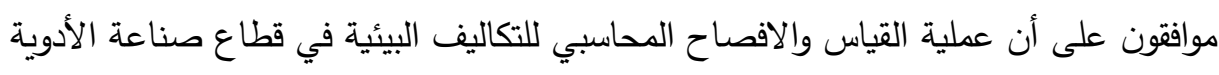
قد تؤدي إلي تلبية احتياجات المستهلكين للمنتجات الصديقة للبيئة وبمعايير الجودة البيئية

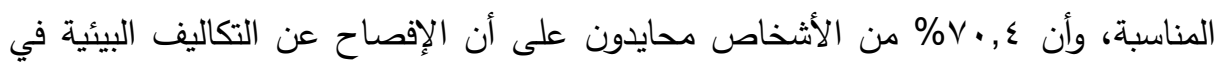

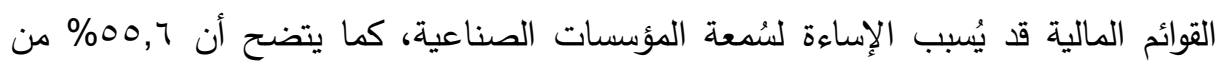

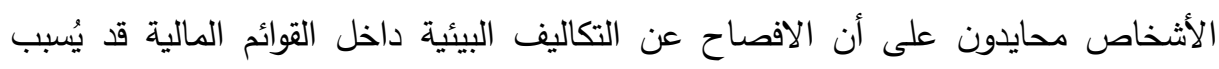

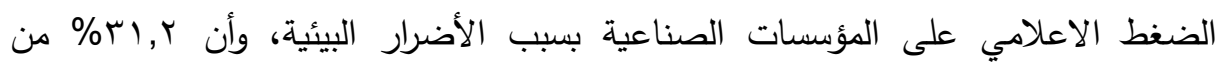

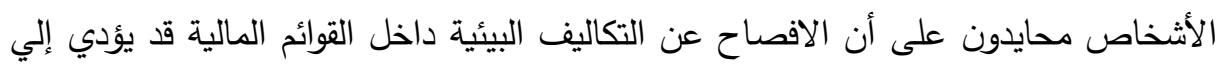
زيادة أعباء المؤسسات الصناعية في الحصول على استثمارات مالية إضافية لحماية البيئة، وأن rvo, \% من الأشخاص موافقون على أن الافصاح عن التكاليف البيئية في القوائم المالية

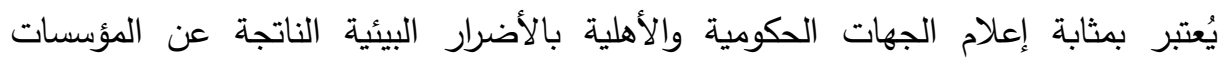

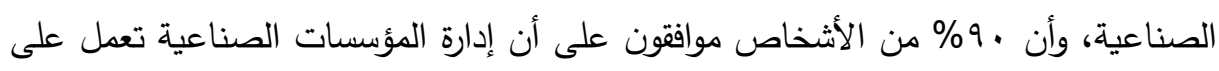

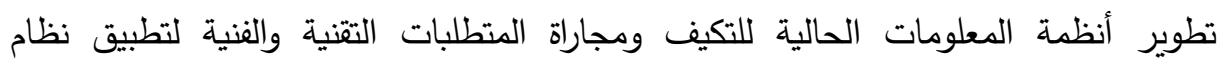
محاسبة التكاليف البيئية، وأن •9\% من الأشخاص موافقون على أن نظام التكاليف الحالي المُطبق لا يعمل على حل كافة المشاكل التي تواجه القياس والافصاح عن التكاليف البيئية. الجدول السابق يوضح إجابات عينة الدراسة لعبارات أثر التكاليف البيئية على جودة القوائم المالية وقيمة المنشاة كانت معظم إجابات عينة الدراسة بالموافقة على جميع العبارات من خلال الإجابة (موافق) وهي النسبة الأكبر والإجابة (محايد)، ثم الإجابتين (موافق بشدة)

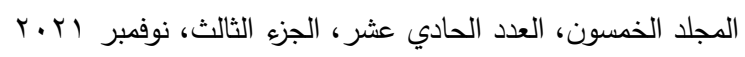

$$
\begin{aligned}
& \text { ISSN 1110-0826 الترقيم الدولي التوني } \\
& \text { الترقيم الدولي الموحد الإكتروني 3178-2636 }
\end{aligned}
$$


(غير موافق) بنسب أقل، مما يثير لموافقة عينة الدراسة على عبارات أثر التكاليف البيئية على جودة القوائم المالية وقيمة المنشاة. الإحصاء الوصفي لفروض الدراسة:

الفرض الأول: لتحليل العلاقة بين قياس أثر التكاليف البيئية وجودة القوائم المالية سوف نثبت لإتهاء صحة الفرض الأول من خلال الجدول التالي. جدول (ب): نتائج التحليل الإحصائي لعبارات أثر التكاليف البيئية على جودة القوائم المالية وقيمة المنشاة

\begin{tabular}{|c|c|c|c|c|c|c|}
\hline المعنويـة & ت & الترتيب & المزين النسئي & الإلمعياري & المستوسطي & العبارات \\
\hline$\cdot, \ldots 1$ & $r v, \diamond V$ & $r$ & $\Lambda \varepsilon, \wedge$ & $\cdot, v_{1}$ & $\varepsilon, Y \leqslant$ & 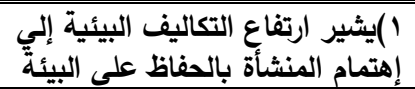 \\
\hline$\cdot, \cdots 1$ & $0,0 r$ & 11 & 74,7 & $\cdot, 9 \leq$ & rr, & 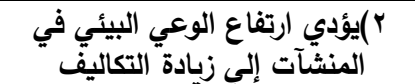 \\
\hline$\cdot, 1$ & $1,0 \wedge$ & ir & $71, \wedge$ & $\cdot, \wedge \wedge$ & $r, . q$ & 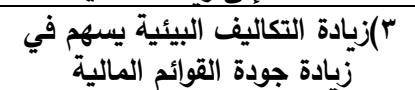 \\
\hline$\cdot, \ldots 1$ & $r \wedge, 10$ & $\varepsilon$ & $\Lambda r$ & • & $\{, 10$ & 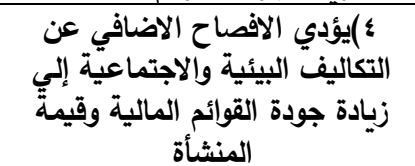 \\
\hline$\cdot, \ldots l$ & $\leq 0,10$ & $r$ & $\wedge \wedge$ & $\cdot, \leqslant 9$ & ـ. & •اليئية قالاجتماعية في المنشآت بمسئولياتها التنمية \\
\hline$\cdot, \ldots l$ & $r \theta, \leqslant \theta$ & 0 & $\Lambda r, r$ &., 79 & $\varepsilon, 11$ & البئية إلّي التأثبير على جيات جودة التكاليف \\
\hline$\cdot, \ldots l$ & $1 \leqslant, 9 V$ & 1. & Vr, & $\cdot, V r$ & r, & 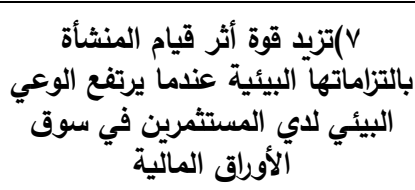 \\
\hline
\end{tabular}


مجلة العلوم البيئية

كلية الدراسات العلا والبحوث البيئية - جامعة عين شس البية

دعاء محمود حرحش وآخرون

\begin{tabular}{|c|c|c|c|c|c|c|}
\hline المعنوية & ت & الترتيب & 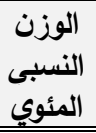 & الإععياري & الحسابي & العبارات \\
\hline 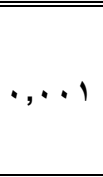 & $r, q 1$ & ir & Tr, \& & • TV & $r, 1 r$ & 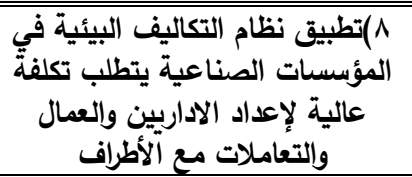 \\
\hline$\cdot, \ldots$ & $19, r$. & $\wedge$ & $v \bullet, \wedge$ & • & $r, v q$ & 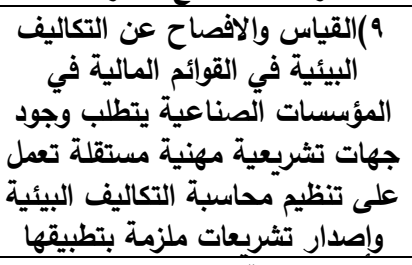 \\
\hline,$\ldots$, & $r \checkmark, \cdot V$ & $v$ & va & $\cdot, O V$ & $r, 90$ & 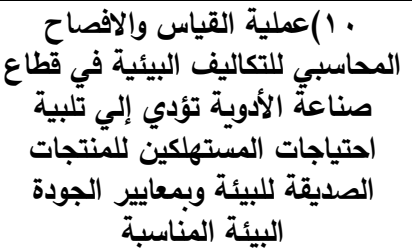 \\
\hline$\cdot, \ldots$ & $r \leq, \leq 70$ & 17 & $\leqslant$ & • & $r, \ldots$ & 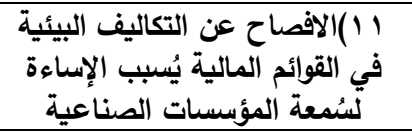 \\
\hline •, & $\cdot, 9 \wedge$. & 10 & $\diamond \wedge, \wedge$ & $\cdot, 9$. & ץ, १६ & 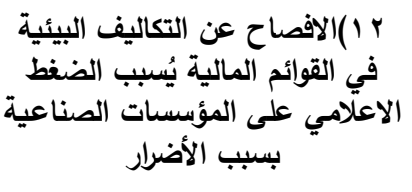 \\
\hline $1, \ldots$ & $\cdot, \ldots$ & $1 \varepsilon$ & 7. & $1, .0$ & $r, \ldots$ & 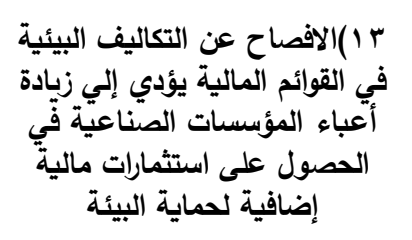 \\
\hline
\end{tabular}

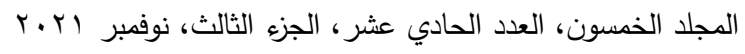

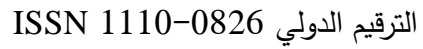

الترقيم الدولي الموحد الإلكتروني 3178-2636 
مجلة العلوم البيئية

كلية الدراسات العلا والبحوث البيئية - جامعة عين شمس لـئة

دعاء محمود حرحش وآخرون

\begin{tabular}{|c|c|c|c|c|c|c|}
\hline المعنوية & ت & الترتيب & المسئبي & المعياري & الحسابي & العبارات \\
\hline$\cdot, \ldots$ & 11,10 & 9 & $v \leqslant, \tau$ & $1, \cdot r$ & $r, v r$ & 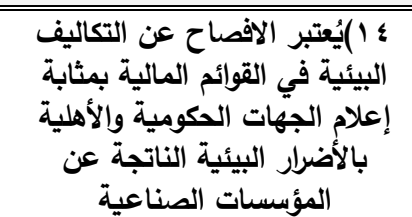 \\
\hline$\cdot, \ldots$ & 19,10 & 7 & A. & $\cdot, \wedge$. & $\varepsilon, \ldots$ & 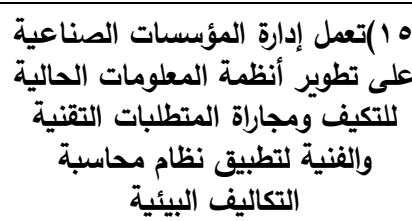 \\
\hline$\cdot, \ldots$ & ג & 1 & 9. & •, TV & $\{, 0$. & 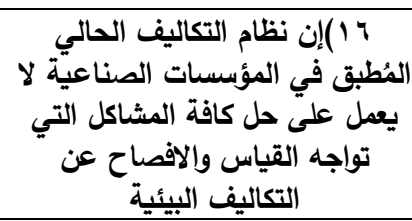 \\
\hline$\cdot, \ldots$ & $\{r, 1\}$ & الثالث & VY, T & • & rד,r & أثقرائك المالية البيئية على جودة المنشاة \\
\hline
\end{tabular}

يتبين من الجدول السابق لوصف عبارات أثر التكاليف البيئية على جودة القوائم المالية

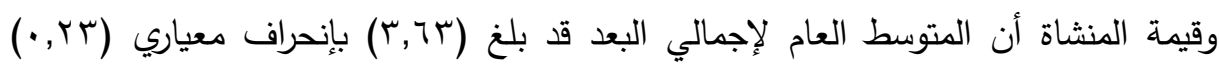

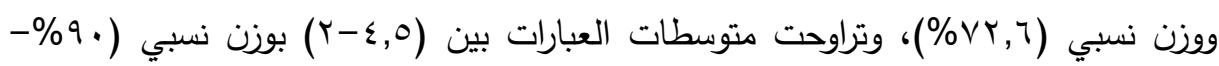
• ؛ \% تثير تلك النسب إلى موافقة عينة الدراسة على أن التكاليف البيئية تؤثر على جودة

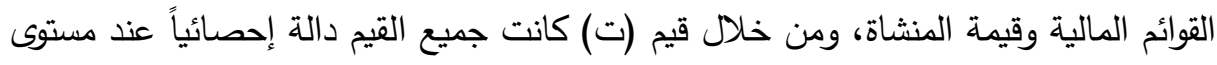
معنوية (0., •) لجميع عبارات بعد أثر التكاليف البيئية على جودة القوائم المالية وقيمة

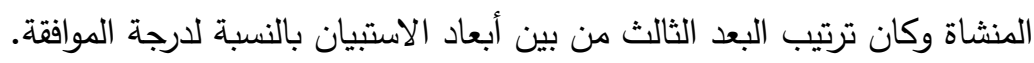

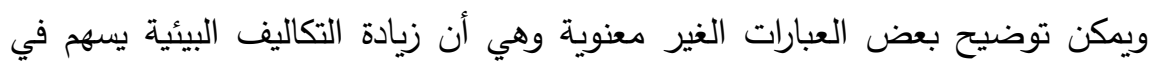
زيادة جودة القوائم المالية بمستوي معنوية ا, , والافصاح عن التكاليف البيئية في القوائم

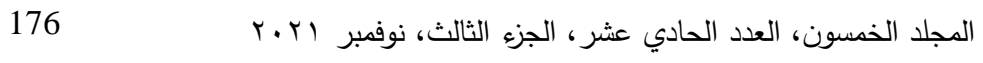
ISSN 1110-0826 الترقيم الدولي التوني الترقيم الدولي الموحد الإكتروني 3178-2636 
المالية يُسبب الضغط الاعلامي على المؤسسات الصناعية بسبب الأضرار البيئية بمستوي

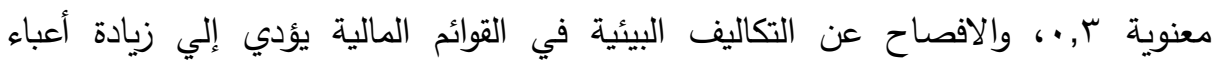
المؤسسات الصناعية في الحصول على استثمارات مالية إضافية لحماية البيئة بمستوي معنوية

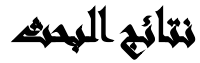

ا ـ القوائم المالية تتأثر تأثير جوهري بعدم افصاح الثركات عن التكاليف البيئية، وذلك بسبب

$$
\text { صعوبة قياسها. }
$$

r • بيان أهمية المعلومات البيئية المفصح عنها داخل القوائم أو التقارير المالية. r. قياس التكاليف البيئية والافصاح عنها يسهم في اتاحة التقارير والقوائم المالية للمعلومات

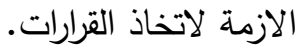

ـ. وجود نماذج محاسبية لقياس التكاليف البيئية في الشركات يُساعد على تطبيقها. ه. قياس التكاليف البيئية يسهم في زيادة ثقة مستخدمي المعلومات المحاسبية. 7. بيان أثر الافصاح عن التكاليف البيئية على جودة القوائم المالية. V. تتأثر المعلومات المحاسبية بسبب عدم قياس التكاليف البيئية.

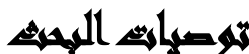

ا ـ تطوير المعايير المحاسبية التي تُلزم الثركات بالقياس والافصاح عن التكاليف البيئية في

تقاريرها وقوائمها المالية من قِبل المنظمات المهنية والجمعيات العلمية المحاسبية.

r. اهتمام الشركات بقياس التكاليف البيئية وعرضها في التقارير والقوائم المالية. r. توسيع مجال الافصاح البيئي من قِبل الشركات ليشمل التقارير المالية، والالتزام بمعايير الافصاح البيئي خدمة لمستخدمي القوائم المالية وحفاظاً على البيئة.

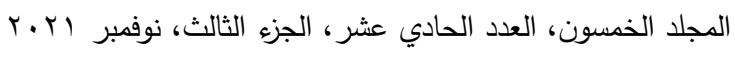

$$
\begin{aligned}
& \text { الترقيم الدولي 0826-0 1110 } \\
& \text { الترقيم الدولي الموحد الإلكتروني 3178-2636-2682 }
\end{aligned}
$$


ـ. ضرورة قيام الشركات بقياس التكاليف البيئية والإفصاح عنها لتحسين جودة المعلومات المحاسبية.

ه. ضرورة الاهتمام بقياس التكاليف البيئية في الشركات على الرغم من صعوبتها، بهدف ايجاد قاعدة جيدة للمعلومات المحاسبية. 7. قيام الشركات بقياس التكاليف البيئية بحيث تكون مُسجلة ومبوبه بشكل واضح ودقية واتيق وعرضها في التقارير والقوائم المالية.

\section{المراليج2}

الحمداني، خليل ابراهيم رجب (11) ب. (1): التحديات التي تواجه قياس التكاليف البيئية. المعهد التقني الموصل، العراق، الطبعة الثانية.

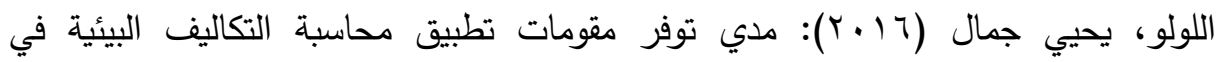

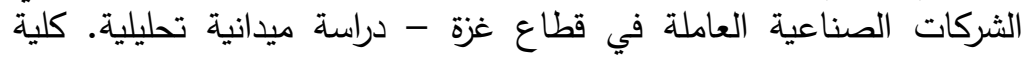

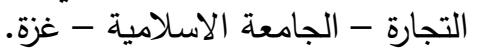

بو عزة، مروة (ع ( ب): مسؤوليات المراجع الخارجي اتجاه الغش في القوائم المالية - دراسة

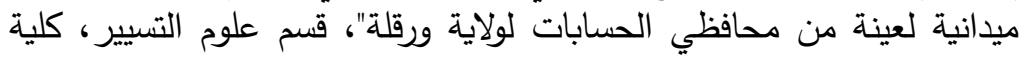

العلوم الاقتصادية والتجارية وعلوم التسيير ، جامعة قاصدية ولية مرباح - ورقلة.

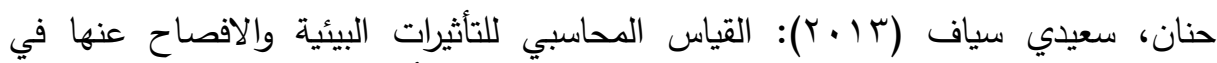

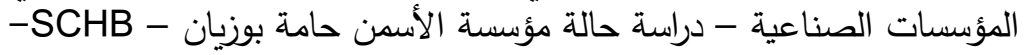
قسنطينة. كلية العلوم الاقتصادية وعلوم التسيير - جامعة قسنطينة التينة

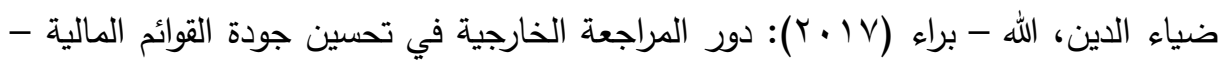

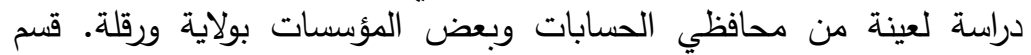
العلوم التجارية - كلية العلوم الاقتصادية والتجارية وعلوم التسيير - جامعة ولية ولتية قاصدي مرباح.

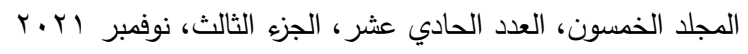

$$
\begin{aligned}
& \text { الترقيم الدولي 0826-0 التئي } \\
& \text { الترقيم الدولي الموحد الإكتروني 3178-2636 }
\end{aligned}
$$




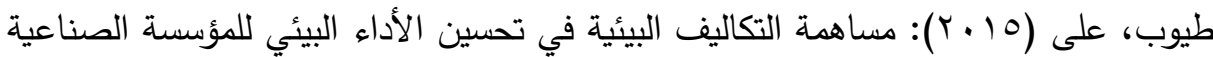

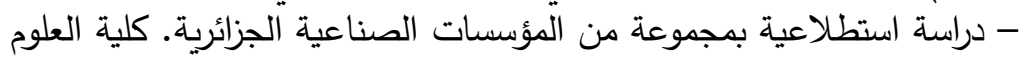

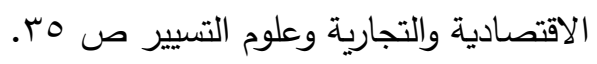

على، عادل حسين: التكاليف البيئية ودورها في تحسين المعلومات المحاسبية المقدمة لاتخاذ

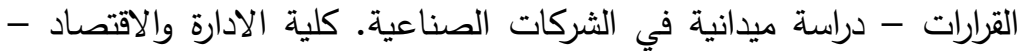

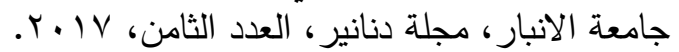

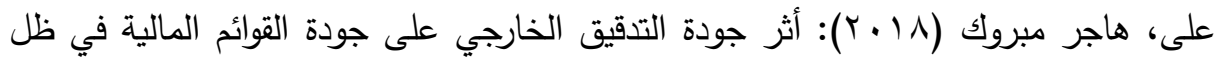

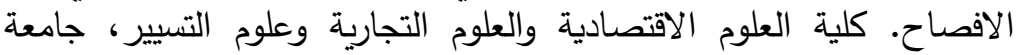

$$
\text { العربي بن مهيدي - أم البواقي. }
$$

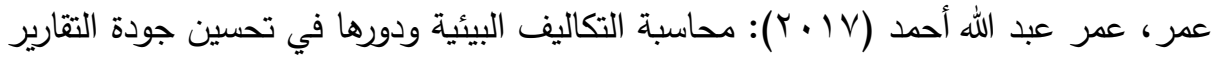

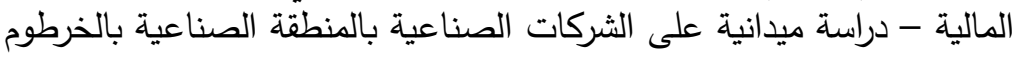

بحري. كلية الدراسات التجارية - جامعة السودان للعلوم والتكنولوجيا.

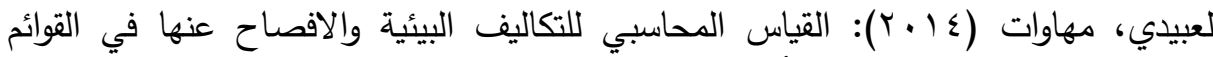

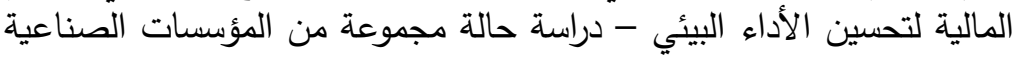
في الجزائر. قسم علوم التسيير، كلية العلوم الاقتصادية والتجارية وعلوم التئية التئية

$$
\text { التسيير، جامعة محمد خيضر بسكره. }
$$

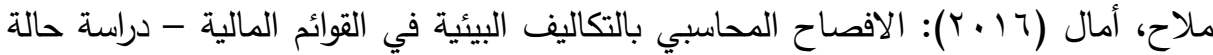

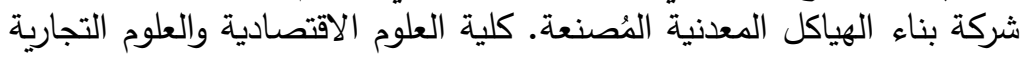

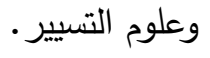

موسي، ياسين عبد الرحيم (1/ ب ب): دور القياس والافصاح عن التكاليف البيئية في جودة

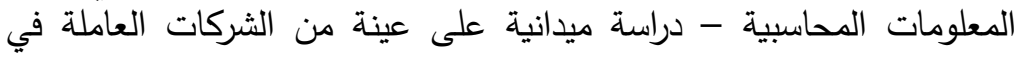
السودان. كلية الدراسات العليا - جامعة السودان للعلوم والتكنولوجيا.

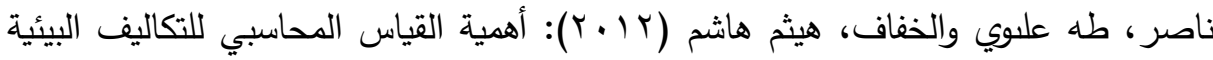

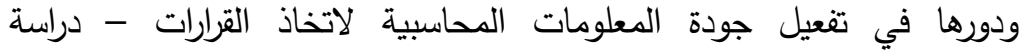
استطلاعية لآراء عينة من المنشآت الصناعية بمدينة الموصل. لماتل

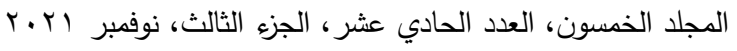

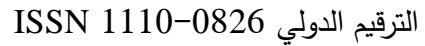

$$
\begin{aligned}
& \text { الترقيم الدولي الموحد الإلكتروني 3178-0826-2636 }
\end{aligned}
$$




$$
\begin{aligned}
& \text { مجلة العلوم البيئية } \\
& \text { كلية الدراسات العلا والبحوث البيئية - جامعة عين شمس لئه } \\
& \text { دعاء محمود حرحش وآخرون }
\end{aligned}
$$

Florence et al:: The Effect Of Identification Of Environmental Cost On Quality Of Disclosure. European Journal Of Business, Economics and Accountancy, Volume 4, Issue 2, 2016 $P P: 37-47$.

Nasreldeen Gidam Elnagy: Measurment and Disclosure About Costs Environmental Quality and Its Impact On The Financial Statement Published. International Journal Of Scientific and Research Publications, Volume 4, Issue 12, December 2014, PP: 1-5.

\title{
MEASURE THE EFFECTS OF ENVIRONMENTAL COSTS AND BENEFITS ON THE QUALITY OF FINANCIAL STATEMENTS IN EGYPTIAN PHARMACEUTICAL COMPANIES
}

\author{
Doaa M. Harhash ${ }^{(1)}$; Tarek A. Hammad ${ }^{(2)}$ \\ and Mahmoud A. Amin (2) \\ 1) Post graduate student at Faculty of Graduate Studies and \\ Environmental Research, Ain Shams University 2) Faculty of \\ Commerce, Ain Shams University
}

\footnotetext{
ABSTRACT

The study dealt with measuring the impact of environmental costs and benefits on the quality of the financial statements. Where the study aimed at the effect of measuring environmental costs and benefits in improving the quality of financial statements and improving the 180

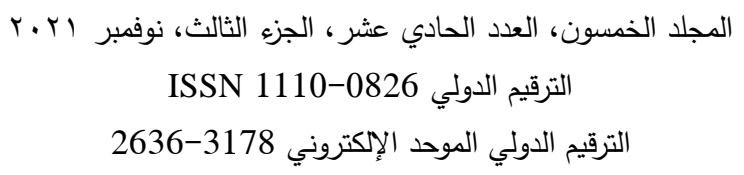




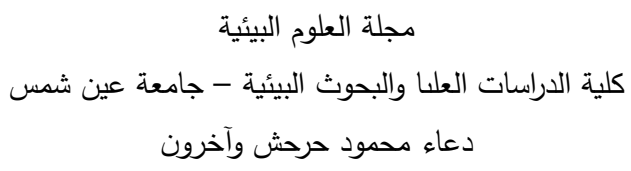

environmental performance in Egyptian pharmaceutical companies, studying the procedures for classifying both environmental costs and benefits in Egyptian pharmaceutical companies to contribute to improving the quality Financial Statements. Does the failure of the financial statements to include environmental costs and benefits affect the quality of the financial statements in Egyptian pharmaceutical companies? Also, is there an impact of measuring environmental costs and benefits in improving the quality of financial statements and improving environmental performance in Egyptian pharmaceutical companies? The study derives its importance from the importance of measuring and disclosing environmental costs and benefits in improving the quality of accounting information. The data of the study were tested from the reality of the field study data, which were collected through (250) questionnaires from a total of (365) questionnaires distributed.

The study concluded that there is a statistically significant effect of measuring environmental costs on the quality of financial reports, as well as an effect of the relationship between measurement Benefits, costs and quality of financial reports. Accordingly, the study hypotheses were accepted.

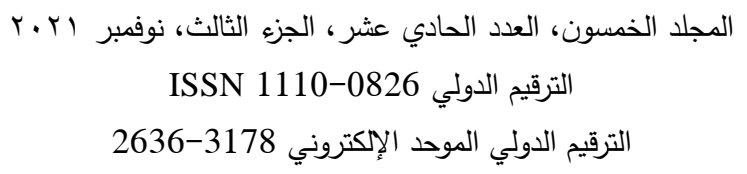

